\title{
High ice water content at low radar reflectivity near deep convection - Part 1: Consistency of in situ and remote-sensing observations with stratiform rain column simulations
}

\author{
A. M. Fridlind ${ }^{1}$, A. S. Ackerman ${ }^{1}$, A. Grandin ${ }^{2}$, F. Dezitter ${ }^{2}$, M. Weber ${ }^{2}$, J. W. Strapp ${ }^{3}$, A. V. Korolev ${ }^{4}$, and \\ C. R. Williams ${ }^{5}$ \\ ${ }^{1}$ NASA Goddard Institute for Space Studies, 2880 Broadway, New York, NY 10027, USA \\ ${ }^{2}$ Airbus Operations S.A.S., 316 route de Bayonne, 31060 Toulouse CEDEX 03, France \\ ${ }^{3}$ Met Analytics Inc., Aurora, Ontario, Canada \\ ${ }^{4}$ Cloud Physics and Severe Weather Research Section, Environment Canada, Toronto, Ontario, Canada \\ ${ }^{5}$ Cooperative Institute for Research in Environmental Sciences, University of Colorado Boulder, \\ and NOAA/Earth System Research Laboratory, Boulder, Colorado, USA
}

Correspondence to: A. M. Fridlind (ann.fridlind@nasa.gov)

Received: 5 May 2015 - Published in Atmos. Chem. Phys. Discuss.: 17 June 2015

Revised: 25 September 2015 - Accepted: 5 October 2015 - Published: 22 October 2015

\begin{abstract}
Occurrences of jet engine power loss and damage have been associated with flight through fully glaciated deep convection at -10 to $-50^{\circ} \mathrm{C}$. Power loss events commonly occur during flight through radar reflectivity $\left(Z_{\mathrm{e}}\right)$ less than 20-30 dBZ and no more than moderate turbulence, often overlying moderate to heavy rain near the surface. During 2010-2012, Airbus carried out flight tests seeking to characterize the highest ice water content (IWC) in such low- $Z_{\mathrm{e}}$ regions of large, cold-topped storm systems in the vicinity of Cayenne, Darwin, and Santiago. Within the highest IWC regions encountered, at typical sampling elevations (circa $11 \mathrm{~km}$ ), the measured ice size distributions exhibit a notably narrow concentration of mass over area-equivalent diameters of $100-500 \mu \mathrm{m}$. Given substantial and poorly quantified measurement uncertainties, here we evaluate the consistency of the Airbus in situ measurements with ground-based profiling radar observations obtained under quasi-steady, heavy stratiform rain conditions in one of the Airbus-sampled locations. We find that profiler-observed radar reflectivities and mean Doppler velocities at Airbus sampling temperatures are generally consistent with those calculated from in situ sizedistribution measurements. We also find that column simulations using the in situ size distributions as an upper boundary condition are generally consistent with observed profiles of $Z_{\mathrm{e}}$, mean Doppler velocity (MDV), and retrieved rain rate. The results of these consistency checks motivate an examina-
\end{abstract}

tion of the microphysical pathways that could be responsible for the observed size-distribution features in Ackerman et al. (2015).

\section{Introduction}

Between 1990 and 1998, commuter transport jets experienced at least 10 incidents of engine power loss near thunderstorms at elevations of $8.5-9.5 \mathrm{~km}$ a.m.s.l. and temperatures of -27 to $-33^{\circ} \mathrm{C}$ (Lawson et al., 1998; Mason et al., 2006). During these incidents the engines lost power slowly prior to abrupt uncommanded reduction of power to idle, commonly referred to as rollback, and in most cases engine power authority was automatically returned after descent through the melting level. Crews reported no more than trace occurrences of hail or graupel. In 1997, industry-sponsored flight tests successfully reproduced a rollback event while circling downwind of continental deep convection at $8.8 \mathrm{~km}$ and $-28^{\circ} \mathrm{C}$ over Alabama, induced by enhanced ice water content (IWC), sustained at likely $0.5-1 \mathrm{~g} \mathrm{~m}^{-3}$ or more over a $10 \mathrm{~km}$ length scale, based on estimates obtained indirectly owing to primary probe failure (Strapp et al., 1999; Mason et al., 2006). On the one hand, the flight tests were deemed a success since a second, modified engine simulta- 
neously experienced no rollback, and no further events have been reported on that particular aircraft since such modifications were made standard (Mason et al., 2006). On the other hand, the industry concluded (e.g., Dezitter et al., 2013) that the inability of current instruments to reliably and accurately measure such high IWC posed a major obstacle to addressing similar hazards being identified in other aircraft types (Strapp et al., 1999, 2005; Mason et al., 2006).

After a period of confusion regarding the potential role of supercooled liquid water owing to the appearance of streaming meltwater on heated cockpit windshields during some events, by 2003 the connection between both commuter and large transport jet engine power loss events and the ingestion of copious ice under glaciated conditions was established, ultimately involving a dozen engine types (Mason and Grzych, 2011). As of 2011, a database of roughly 100 documented events of jet engine power loss or damage connected with the engine core had indicated several patterns in the meteorological conditions encountered (Grzych and Mason, 2010; Mason and Grzych, 2011). Namely, events occurred almost exclusively near deep convection, under hypothesized and sometimes unambiguously fully glaciated conditions, in the absence of pilot-reported equivalent radar reflectivity $\left(Z_{\mathrm{e}}\right.$, less than $\left.20-30 \mathrm{dBZ}\right)$ or more than moderate turbulence at flight level. Hereafter we will refer to event-related microphysical conditions as "high IWC-low- $Z_{\mathrm{e}}$ " conditions, where the IWC designation remains qualitative or relative, as discussed further below, and the $Z_{\mathrm{e}}$ threshold is based on radar sensitivity, without any specified relation to convective or stratiform structures

Outside of these commonalities, events occupied a rather wide envelope of storm conditions: $38 \%$ occurred within an oceanic mesoscale convective system (MCS), where pilots typically flew directly through the central and deepest clouds owing to a complete lack of detectable $Z_{\mathrm{e}}$ at flight altitude and no identification otherwise of flight-level convective cores; $34 \%$ occurred within a strong tropical MCS, where pilots detected convective cores at flight altitude, but maneuvered to avoid them, typically passing over regions of heavy rain; $8 \%$ occurred in a continental MCS, where pilots again detected and diverted around cores at flight altitude, flying over heavy rain regions; $6 \%$ occurred in classical continental anvils, where cores were identified and avoided on the downwind side of storms, in this case without significant rain immediately below; and the remainder occurred variously within tropical multicell, elevated warm frontal, vigorous winter lake-effect, or developing, immature, continental convection (Mason and Grzych, 2011).

To evaluate event distribution geographically and seasonally, Grzych and Mason (2010) derived maps of high IWClow- $Z_{\mathrm{e}}$ frequency, based on statistical comparison of reanalysis model fields with the following event conditions: high precipitable water (median of $6 \mathrm{~cm}$ ), marginal to modest atmospheric instability (median convectively available potential energy of $1400 \mathrm{~J} \mathrm{~kg}^{-1}$ ), and modest wind shear (gener- ally sufficient to support squall lines). When also considering flight traffic frequency, these maps generally explained the concentration of events within $45^{\circ}$ of the equator under preferentially moist conditions seasonally.

It is notable that the MCS class events documented $(80 \%$ of the total) occurred beneath a cirrus anvil shield of at least $185 \mathrm{~km}$ in maximum dimension. However, an analysis of temperature instrument errors caused by high IWC-low- $Z_{\mathrm{e}}$ conditions during some events has suggested that enhanced IWC regions might commonly be as short as $O(10 \mathrm{~km})$ in length, making it impossible to rule out the sufficiency of either long or short duration exposure to cause such events (Mason et al., 2006). An exhaustive analysis of conditions encountered with and without power loss events led to only one consistently recommended hazard detection action available using current cockpit instrumentation: use the aircraft radar's tilt and gain to scan below the freezing level for moderate to heavy rain (Grzych and Mason, 2010; Mason and Grzych, 2011).

\section{Microphysical conditions}

From the perspective of industry, the most recent effort to rigorously establish the condensed water content possible in convection was undertaken by the Royal Aircraft Establishment in the 1950s using a pitot-type tube that collected ice and water condensate in a thermostatically controlled heated tube and delivered it to a measuring system inside the aircraft (McNaughton, 1959; Mason et al., 2006). Measurements were made at roughly $10 \mathrm{~km}$ resolution over a temperature range of 0 to $-26^{\circ} \mathrm{C}$, with little reference to $Z_{\mathrm{e}}$ or degree of glaciation encountered. Regions of the highest expected turbulence and water content were avoided for reasons of safety, but the flight paths were also adjusted to find and maintain high water content in order to challenge engine performance. Based on roughly 200 cloud traverses in the vicinity of Entebbe, Singapore, and Darwin, maximum total water contents encountered were in excess of 6 and $5 \mathrm{~g} \mathrm{~m}^{-3}$ over length scales of 10 and $100 \mathrm{~km}$, respectively, and more than $5 \%$ of all reported measurements at each location exceeded $2 \mathrm{~g} \mathrm{~m}^{-3}$, with an accuracy of $15 \%$ estimated at that time.

Motivated by the 1990s commuter jet engine power loss problem, Lawson et al. (1998) reanalyzed more limited in situ measurements collected within anvils over Montana during the Cooperative-Convective-PrecipitationExperiment (CCOPE) (Knight, 1982) and near the Tiwi Islands during the Central Equatorial Pacific Experiment (CEPEX) (Heymsfield and McFarquhar, 1996; McFarquhar and Heymsfield, 1996). Since no direct measurements of IWC were obtained during these campaigns, it was calculated from the most suitable data available. From CCOPE, IWC was calculated from a particle measuring systems (PMS) two-dimensional precipitation (2DP) probe and scan- 
ning radar reflectivity fields co-located with flight tracks, with an estimated accuracy of $50 \%$ (Heymsfield and Palmer, 1986; Heymsfield, 1986). From CEPEX, IWC was calculated from a PMS two-dimensional cloud particle probe (2DC), with an estimated accuracy of a factor of 2, owing largely to sensitivity to mass-dimension relationships applied, plus roughly $50 \%$ attributed to particle counting uncertainty (McFarquhar and Heymsfield, 1996). The 2DP and 2DC probes respectively measure particles that are nominally 300-9600 and $30-1800 \mu \mathrm{m}$ in maximum dimension of randomly oriented projected area $\left(D_{\max }\right.$; the diameter of the smallest circle enclosing two-dimensional projections of ice particles imaged at random orientation in situ). Working in the absence of recorded $Z_{\mathrm{e}}$ at flight level from these scientific research campaigns, Lawson et al. (1998) reported peak anvil IWC of $1-3 \mathrm{~g} \mathrm{~m}^{-3}$, with a suggested factor-of-2 uncertainty, falling to well below $1 \mathrm{~g} \mathrm{~m}^{-3}$ at a distance of $50 \mathrm{~km}$ from storm locations of highest $Z_{\mathrm{e}}$, a vicinity commonly reported for initiation of commuter and large transport jet engine events (Mason et al., 2006). Ice size-distribution properties were not extensively analyzed, except to report the largest particles encountered, which were commonly on the order of $2 \mathrm{~mm}$ in $D_{\text {max }}$.

In a more detailed analysis of ice properties in three CEPEX anvils at elevations of $7-14 \mathrm{~km}$ and temperatures of -15 to $-65^{\circ} \mathrm{C}$, where convection was approached as closely as the pilots considered safe, McFarquhar and Heymsfield (1996) reported a predominance of irregular, plate-like, compact spatial crystals and irregular aggregates in the highest IWC regions (0.1-1 $\mathrm{g} \mathrm{m}^{-3}$, calculated as described above). They reported typical mass median $D_{\max }\left(\mathrm{MMD}_{\max }\right.$; the $D_{\max }$ above and below which half of mass resides) decreasing from 500 to $100 \mu \mathrm{m}$ with increasing height. Prominent peaks in the mass size distribution were found at 150 $600 \mu \mathrm{m}$. Even if IWC were as high as $4 \mathrm{~g} \mathrm{~m}^{-3}$, Fig. 1 illustrates that such relatively small mass median diameters would be associated with $Z_{\mathrm{e}}$ less than $20 \mathrm{dBZ}$ if present in monomodal size distributions with typical assumptions regarding ice crystal properties (furthermore, we note that such calculations do depend strongly on assumed ice crystal mass-dimension characteristics, which are not directly measured by any current instruments, as well as size distribution properties).

Based on measurements during the Tropical Composition, Cloud and Climate Coupling Experiment (TC4) campaign over Central America (Toon et al., 2010), reportedly the most extensive tropical anvil measurement campaign since CEPEX (Lawson et al., 2010), and the NASA African Monsoon Multidisciplinary Analyses (NAMMA) campaign over West Africa (http://airbornescience.nsstc.nasa.gov/namma/), the ice mass size distributions in fresh anvils, aged anvils, and convective turrets alike were consistently found to be dominated by crystals with $D_{\max }$ of 100-400 $\mu \mathrm{m}$ (Lawson et al., 2010). During both TC4 and NAMMA, fresh anvils contained columns, capped columns, relatively compact ir-

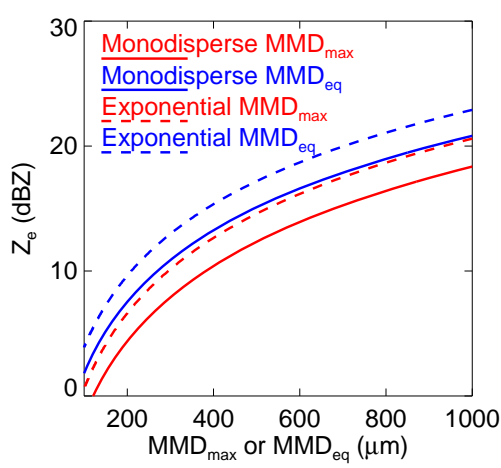

Figure 1. For an ice water content of $4 \mathrm{~g} \mathrm{~m}^{-3}$ with a monomodal ice number size distribution that is either monodisperse or exponential in shape, equivalent radar reflectivity $\left(Z_{\mathrm{e}}\right)$ as a function of mass median maximum dimension $\left(\mathrm{MMD}_{\max }\right)$ for ice particle properties following Baker and Lawson (2006, their Table 1) and mass median area-equivalent diameter $\left(\mathrm{MMD}_{\mathrm{eq}}\right)$ for ice particle properties following Eq. (1) (Locatelli and Hobbs, 1974).

regular crystals and irregular aggregates that were generally smaller than $2 \mathrm{~mm}$ in $D_{\max }$, whereas turrets contained $1-2 \mathrm{~mm}$ graupel over a wide temperature range $(-10$ to $-50{ }^{\circ} \mathrm{C}$ ). Considering this diversity of new data with strikingly similar microphysical features, Lawson et al. (2010) attributed the predominance of several hundred micron particles to cloud droplets freezing heterogeneously at temperatures colder than $-12{ }^{\circ} \mathrm{C}$ and then growing by vapor deposition, while smaller and larger outflow ice preferentially evaporated and sedimented, respectively.

During TC4, IWC was calculated by applying the habitindependent area-dimensional relation derived in Baker and Lawson (2006) to measurements from an underwing mounted PMS two-dimensional stereo (2DS) probe over a size range of roughly $10-3000 \mu \mathrm{m}$ in $D_{\max }$. Calculated IWC was shown to agree with direct measurements from a counterflow virtual impactor (CVI) inlet mounted on the fuselage of the aircraft to within $20 \%$ on average at IWC concentrations below $0.5 \mathrm{~g} \mathrm{~m}^{-3}$, the estimated saturation of that instrument under TC4 measurement conditions (Lawson et al., 2010). Within a heated CVI inlet, impacted ice is evaporated into a dry airstream, which is in turn sampled by a Lyman- $\alpha$ hygrometer; IWC uncertainty is estimated to be $10 \%$ for values larger than $0.2 \mathrm{~g} \mathrm{~m}^{-3}$ (Twohy et al., 1997). Lawson et al. (2010) do not offer an estimate of uncertainty in IWC calculated or measured during TC4 or NAMMA. Although IWC exceeding $2 \mathrm{~g} \mathrm{~m}^{-3}$ was calculated in one convective turret, maxima were less than $1 \mathrm{~g} \mathrm{~m}^{-3}$ in fresh and aged anvil regions.

In a data set compiled for development of satellite retrieval algorithms, comprising thousands of $5 \mathrm{~s}$ averaged aircraft data from TC4, NAMMA, and other campaigns, IWC values greater than $2 \mathrm{~g} \mathrm{~m}^{-3}$ are very rare (Delanoë et al., 2014). Furthermore, we note that no research aircraft involved encoun- 
tered engine power loss events although high IWC-low- $Z_{\mathrm{e}}$ conditions were not specifically avoided, to our knowledge.

Comparison of IWC retrievals using CloudSat data $\left(25^{\circ} \mathrm{S}-25^{\circ} \mathrm{N}\right)$ from 7 July to 16 August 2006 over the tropics $\left(25^{\circ} \mathrm{S}-25^{\circ} \mathrm{N} ; \sim 1.8 \mathrm{~km} \times 1.4 \mathrm{~km} \times 0.5 \mathrm{~km}\right.$ resolution) showed rare occurrences of greater than $2.5 \mathrm{~g} \mathrm{~m}^{-3}$ at $10 \mathrm{~km}$ in elevation (frequency of less than $10^{-8}$ ) from two out of three algorithms (Wu et al., 2009). However, a third algorithm showed occurrences of IWC exceeding $10 \mathrm{~g} \mathrm{~m}^{-3}$, and the spread of algorithm results diverged sharply at IWC values greater than $1 \mathrm{~g} \mathrm{~m}^{-3}$.

Motivated directly by the engine power loss problem, a more recent satellite-based study aimed to establish IWC conditions conceivably encountered by commercial aircraft flying at an elevation of $10 \mathrm{~km}$ in the tropics using CloudSat and CALIPSO measurements and retrievals (Gayet et al., 2014). After identifying and analyzing a well-observed tropical MCS off the equatorial coast of Brazil, they concluded it likely that the storm included an area wider than $55 \mathrm{~km}$ with IWC greater than $1 \mathrm{~g} \mathrm{~m}^{-3}$ and $94 \mathrm{GHz} Z_{\mathrm{e}}$ below $18 \mathrm{dBZ}$, including $2.5 \mathrm{~km}$ footprint peaks of $2-4 \mathrm{~g} \mathrm{~m}^{-3}$, with a large uncertainty owing to unknown ice morphological and size distribution properties. For an ice mass mixing ratio of $4 \mathrm{~g} \mathrm{~m}^{-3}$, Fig. 1 illustrates the relationship of $\mathrm{MMD}_{\max }$ to reflectivity for the simplest case of monodisperse ice particles with mass following Eq. (1), and for exponential size distributions with slopes over an observation-based range of $1-1000 \mathrm{~cm}^{-1}$ (Heymsfield et al., 2013). Holding size distribution properties fixed, denser ice particles would lead to increasing reflectivity for the same $\mathrm{MMD}_{\max }$ and ice mass mixing ratio.

Focusing briefly on observed ice morphology, the McFarquhar and Heymsfield (1996) and Lawson et al. (2010) studies both identify a sharp distinction between crystal shapes seen in deep convection outflow vs. those seen in cirrus that are formed in situ. Although both may contain a mixture of habits that include irregular and rather compact appearing particles of several hundred microns in $D_{\max }$, cirrus formed in situ are most commonly characterized by a notably larger fraction of rosettes (Lawson et al., 2010, per their Fig. 2). Although not reported from TC4 or NAMMA, deep convection that is electrically active may also be distinguished by a predominance of chain aggregates (Stith et al., 2004), which have been found to be composed of small frozen droplets or faceted crystals with $D_{\max }$ commonly less than $\sim 25-100 \mu \mathrm{m}$ (e.g., Connolly et al., 2005; Gayet et al., 2014; Stith et al., 2014). The occurrence of chain aggregates is attributed to the presence of electric fields sufficient to enhance the aggregation process, as well as sufficiently many such small crystals to aggregate, perhaps owing to homogeneous freezing of abundant cloud droplets in the strong, mixed-phase updrafts associated with electrical activity (e.g., Connolly et al., 2005). As discussed further below, the complexity of crystal morphology contributes substantially to uncertainty in the relationship between IWC, ice mass size distribution, and $Z_{\mathrm{e}}$ in clouds associated with deep convection.
In this two-part study, we examine a set of measurements gathered by Airbus during 2010-2012 in deep convection near Cayenne, Darwin, and Santiago. As described by Grandin et al. (2014), an Airbus objective was to obtain preliminary measurements to evaluate newly proposed standards for engine performance in glaciated icing conditions (Mazzawy et al., 2007). Conditions sampled included oceanic and continental conditions, monsoonal and sea breeze convection, and a range of storm size extents. Similar to the McNaughton (1959) campaigns, the purpose was to find and stay within the highest IWC regions possible. Here in Part 1, we first survey the IWC, mass size distribution, and $Z_{\mathrm{e}}$ derived from measurements; these are the factors immediately relevant to characterizing high $\mathrm{IWC}-\mathrm{low}-Z_{\mathrm{e}}$ conditions. We compare the flight test data with previous literature and with remote-sensing measurements of a well-observed MCS over Darwin during the Tropical Warm Pool International Cloud Experiment (TWP-ICE) campaign (May et al., 2008). Finally, we use Airbus observations to initialize steady-state column simulations of heavy stratiform rain columns, and compare predicted $Z_{\mathrm{e}}$ and Doppler fall speed profiles with observations. Aside, we note that although many power loss events may be within a region classified as stratiform rain by some measure (Grzych and Mason, 2010), it is not clear whether power loss events are associated with classical stratiform rain columns (Biggerstaff and Houze, 1991), commonly associated with a radar reflectivity bright band (e.g., Steiner et al., 1995), or some type of transitional regime. A transitional regime region is already difficult to objectively define in a mid-latitude squall line (cf. Biggerstaff and Houze, 1993), where convective and stratiform rain regions are commonly well separated, and is more complicated in large tropical systems owing to the variety of convective region structure (e.g., Mapes and Houze, 1992). Here simulations are limited to heavy stratiform rain regions in order to make use of Doppler fall speed information under relevant quiescent conditions where mean vertical wind can be neglected at elevations circa $11 \mathrm{~km}$ relative to reflectivityweighted ice fall speed.

\section{Airbus in situ measurements}

The Airbus flight campaigns included two in situ probes intended to maintain functionality under high IWC conditions: a newly designed Science Engineering Associates (SEA) Robust solid hot-wire probe used for estimation of ice mass mixing ratio (cf. Strapp et al., 2005) and an Airbus imaging nephelometer designed for measurement of liquid droplet size distribution but used here for estimation of ice mass size distribution (Roques, 2007; Dezitter et al., 2013; Grandin et al., 2014).

Since about 2005, it has been realized that hot-wire devices using trapping geometries are subject to relatively low capture efficiencies owing to re-entrainment of only 
a fraction of particles that bounce out of the capture volume (Emery et al., 2004; Strapp et al., 2005; Korolev et al., 2013 b). The Robust probe was developed primarily to provide surrogate IWC measurements for the calibration of a wind tunnel producing high IWC at relatively high wind speed (Strapp et al., 2008), conditions where essentially all available hot-wire probes were known or suspected to fail owing to particle impact damage (Strapp et al., 1999). In a wind tunnel, Robust probe measurements were intended to be used alongside ice ingestion measurements to deduce absolute IWC and ice mass size distributions. During the course of calibrations, the efficiency of the capture, melting, and evaporation by the Robust probe for shaved ice particles was estimated at about 0.4 , the value assumed here. The probe was subsequently recommended to Airbus on the basis of durability and its simple principle of operation, requiring a relatively simple installation, to provide real-time guidance during flight tests.

The accuracy of applying a 0.4 collection efficiency to estimate IWC from the Robust probe under natural ice particle conditions remains unknown and will require further investigation (Grandin et al., 2014). Comparisons with IWC estimated from the imaging nephelometer in Airbus flight tests has indicated smaller efficiencies of 0.2-0.3 (Grandin et al., 2014). Although the IWC accuracy was initially estimated as $30 \%$ (assuming the primary source of error to be the loss of re-entrained mass, such that measurements uncorrected for efficiency should provide an accurate lower limit on IWC), we can offer no further evidence of accuracy here to establish anything better than the raw factor of 2 uncertainty owing to overall collection efficiency. Recent flight tests have provided a data set that is hoped will improve efficiency characterization in the near future (Grandin et al., 2014). Because the probe's efficiency for liquid water content is close to unity, such that liquid and ice contributions to mass cannot be accurately determined, in Fig. 2 we include only measurements taken at temperatures colder than $-20^{\circ} \mathrm{C}$, where airframe icing was non-existent or negligible; size-distribution measurements are limited to temperatures colder than $-33^{\circ} \mathrm{C}$, as discussed further below.

In Fig. 2 the total condensed water content (CWC; liquid plus ice) reported by the Robust probe during each campaign is plotted as a function of elevation over three averaging lengths: $0.2 \mathrm{~km}$ ( $1 \mathrm{~Hz}$ data as reported, at typical airspeed of $\left.200 \mathrm{~m} \mathrm{~s}^{-1}\right), 2.5$, and $10 \mathrm{~km}$. Data include eight flights from Cayenne (F1419-F1426), six flights from Darwin (F1403F1409), and nine flights from Santiago (F1539-F1547). We note that the Cayenne and Darwin flights targeted cruise elevations circa $10 \mathrm{~km}$, whereas the Santiago flights targeted warmer temperatures; the concentration of IWC as a function of elevation at each location should therefore be viewed primarily as an indication of sample frequency. Based on a more detailed analysis of the Cayenne and Darwin Robust probe data as a continuous function of length scale within identified legs, Grandin et al. (2014) report that 99th percentile
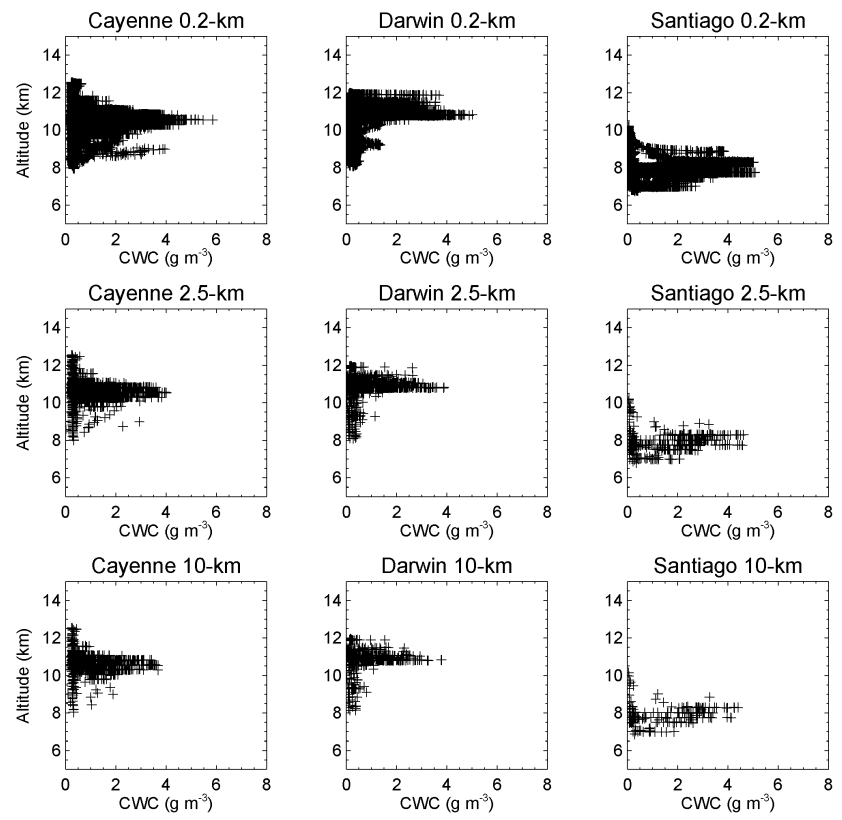

Figure 2. Total condensed water content (CWC) measurements by the Robust probe during flight tests from Cayenne (left column), Darwin (middle column), and Santiago (right column). Measurements are included only for air temperatures were below $-20^{\circ} \mathrm{C}$, where liquid water contributions are expected to be negligible. Considering a typical air speed of $200 \mathrm{~m} \mathrm{~s}^{-1}, 1 \mathrm{~Hz}$ measurements corresponding to a horizontal length scale of roughly $0.2 \mathrm{~km}$ (top row) slightly exceed those averaged over 2.5 and $10 \mathrm{~km}$ length scales.

CWC is a surprisingly weak function of length scale over 2 orders of magnitude $(0.2-20 \mathrm{~km})$, consistent with the pattern seen here across all three locations in Fig. 2. They also show that a leg with statistically extreme peak CWC does exhibit a sharper decrease in CWC with averaging distance, as might be expected within a narrow updraft, for instance.

Taken together, the envelope of measurements is qualitatively similar to that reported by McNaughton (1959) insofar as $10 \mathrm{~km}$ mean condensate mixing ratios in excess of $2 \mathrm{~g} \mathrm{~m}^{-3}$ are found in all three locations. At a length scale of $10 \mathrm{~km}, 2 \mathrm{~g} \mathrm{~m}^{-3}$ is roughly twice the maximum value shown across the three CEPEX anvils examined by McFarquhar and Heymsfield (1996, cf. their Fig. 3). During TC4, $2 \mathrm{~g} \mathrm{~m}^{-3}$ was only reported at a length scale of $O(1 \mathrm{~km})$ in an updraft exceeding $20 \mathrm{~m} \mathrm{~s}^{-1}$ (Lawson et al., 2010). TC4 IWC at a $10 \mathrm{~km}$ length scale reached at least $0.25 \mathrm{~g} \mathrm{~m}^{-3}$ in fresh anvils, and mean anvil IWCs reported appear generally consistent with CEPEX data (McFarquhar and Heymsfield, 1996; Lawson et al., 2010). On the face of it, these results may seem statistically inconsistent; however, at least some degree of difference could be explained by the objective of the Airbus flight tests to sample very large, cold-topped storms and to prioritize the repeated measurement of the highest IWC found there. A large database of such measurements does not currently exist. Other differences may be within the large and 


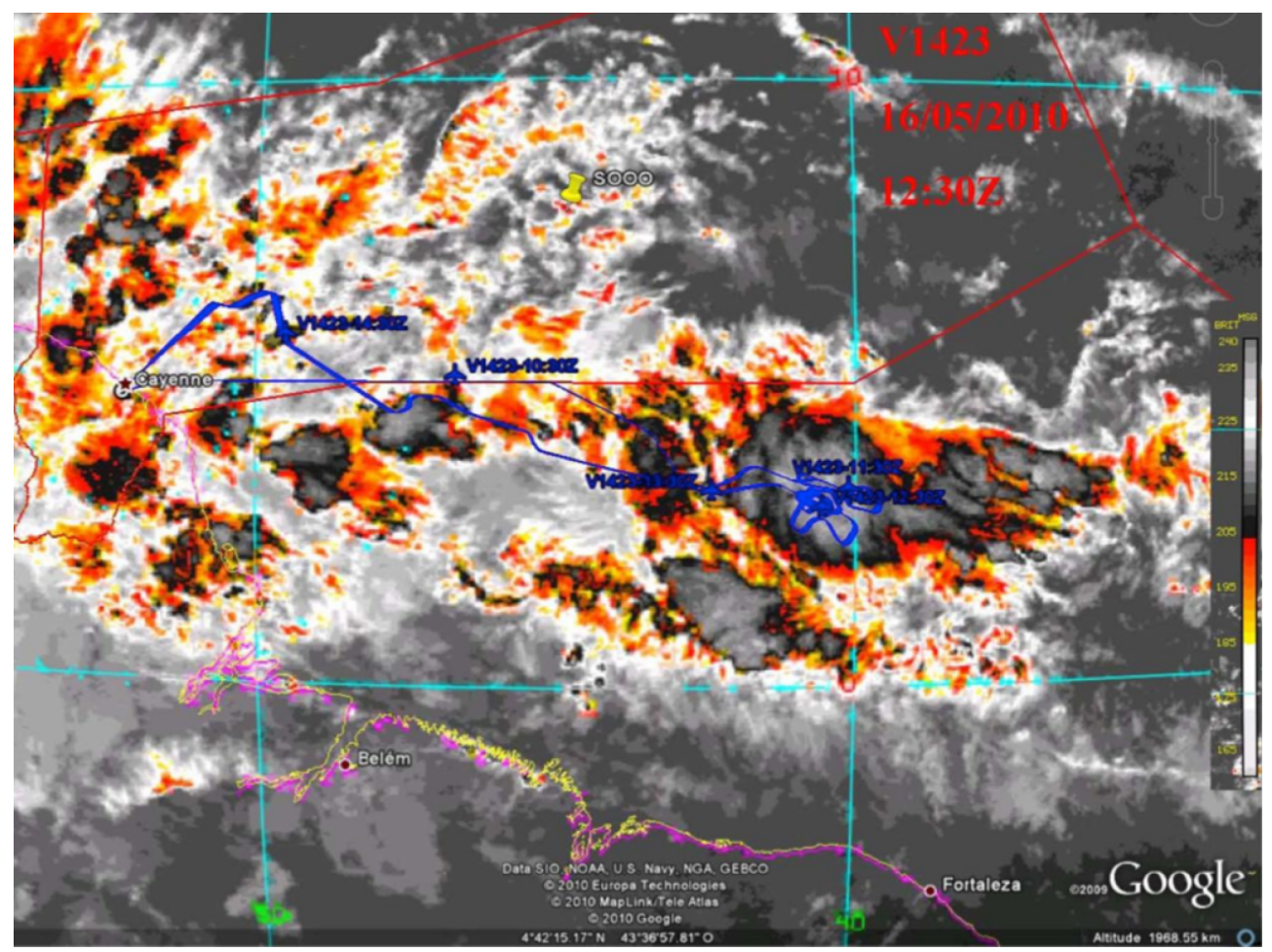

Figure 3. Cayenne flight F1423 track over brightness temperature from Meteosat 9 channel 10 at 12:45 UTC on 16 May 2010.

poorly quantified uncertainty of both measured and calculated IWC values.

We next consider in greater detail the measurements obtained during a flight that encountered relatively high IWC. From the track of Cayenne flight F1423 (Fig. 3), with spirals in an identified high IWC-low- $Z_{\mathrm{e}}$ region at circa $11 \mathrm{~km}$ in altitude, Fig. 4 shows ice particle number size distributions derived from the nephelometer measurements. At temperatures circa $-43^{\circ} \mathrm{C}$ during the flight segment analyzed (Fig. 5), the sampled cloud is fully glaciated. While capped columns are commonly present (see Ackerman et al., 2015, hereafter Part 2), the majority of crystals appear irregular, as found in CEPEX anvils (cf. McFarquhar and Heymsfield, 1996), and the nephelometer images do not commonly produce images of sufficient clarity to distinguish rime or other morphological details. The nephelometer size distributions are reported as a function of area-equivalent diameter $\left(D_{\text {eq }}\right)$, defined as the diameter of a circle with area equal to the twodimensional projection of an ice particle imaged at random orientation in situ, over a bin midpoint range of $67.5 \mu \mathrm{m}$ to $3 \mathrm{~mm}$. Also shown is the mass size distribution calculated assuming a widely used relationship of particle $m$ in mg to $D_{\text {eq }}$ in $\mathrm{mm}$ derived from measurements of natural crystals sampled in the Cascade Mountains, Washington (Locatelli and Hobbs, 1974):

$m=0.037 D_{\mathrm{eq}}^{1.9}$.
Here we apply this relation using the same dimension $D_{\text {eq }}$ defined by Locatelli and Hobbs (1974) for their singleparticle measurements, applicable both to aggregates of densely rimed radiating assembles of dendrites or dendrites ( $D_{\text {eq }}$ of 2-12 $\mathrm{mm}$ measured) and to aggregates of unrimed radiating assemblages of plates, side planes, bullets, and columns ( $D_{\text {eq }}$ of $1-3 \mathrm{~mm}$ measured). Aside, we note that this $D_{\text {eq }}$ is slightly different from the average of chord lengths parallel and perpendicular to a photodiode array substituted in Brown and Francis (1995). Whereas this $m-D_{\text {eq }}$ relation was derived from particles with $D_{\text {eq }}$ of 1-12 mm (based on roughly fifty particles total), it is applied here at all $D_{\text {eq }}$, with the exception that effective density is limited to that of bulk ice, which is relevant where $D_{\text {eq }}$ is smaller than $\sim 100 \mu \mathrm{m}$; such small particles do not contribute substantially to the mass size distributions shown here, though bin-wise uncertainty in mass size distributions calculated using this approach is not quantifiable at this time. As discussed above, roughly a factor of 2 uncertainty in calculated IWC may be associated with uncertainty in the validity of Eq. (1) or another such relationship (e.g., McFarquhar and Heymsfield, 1996). Also shown in Fig. 4 are Rayleigh radar reflectivities calculated from the ice mass size distributions as the integral of the sixth moment of the melted diameter multiplied by a dielectric factor of $0.208 / 0.93$ (Smith, 1984).

As mentioned above, here we focus primarily on the mass and radar reflectivity that contribute to high IWC-low- $Z_{\mathrm{e}}$ conditions. Figure 5 shows the time series of integrated 

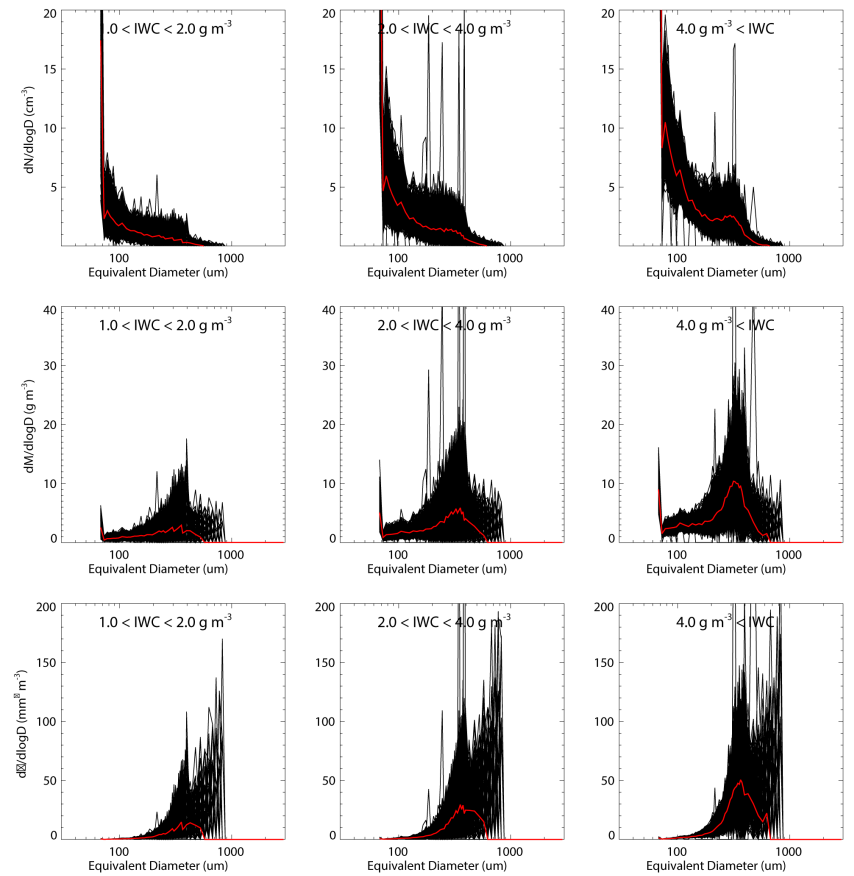

Figure 4. Cayenne flight F1423 ice number size distribution (top row), mass size distribution (middle row), and equivalent radar reflectivity size distribution (bottom row) in three ice water content (IWC) ranges: $1-2 \mathrm{~g} \mathrm{~m}^{-3}$ (left column), 2-4 $\mathrm{g} \mathrm{m}^{-3}$ (middle column), and $>4 \mathrm{~g} \mathrm{~m}^{-3}$ (right column). Measurements from the analyzed time period 11:30-13:20 UTC on 16 May 2010, during spirals within an MCS (cf. Figs. 3 and 5). Red line indicates bin-wise median size distribution.

IWC, mass median $D_{\text {eq }}\left(\mathrm{MMD}_{\mathrm{eq}}\right)$, and $Z_{\mathrm{e}}$ obtained from the measured size distributions. Here it is shown that IWC obtained from the Robust probe closely tracks IWC obtained from integration of calculated mass size distributions over roughly $0.1-4 \mathrm{~g} \mathrm{~m}^{-3}$ reported, with the mass calculated from the nephelometer exceeding that from the Robust probe by roughly $25 \%$ at the highest values reported. Calculated $Z_{\mathrm{e}}$ values are below $15 \mathrm{dBZ}$, although the sharp drop in $Z_{\mathrm{e}}$ size distributions at the largest particles sizes indicates that the nephelometer size distributions do not include the largest particles contributing to calculated $Z_{\mathrm{e}}$ in all three mass ranges shown, so this calculated $Z_{\mathrm{e}}$ is low by an unknown amount. However, mass size distributions do not appear to be as truncated as $Z_{\mathrm{e}}$ size distributions; although they must also be truncated to some degree by an unknown amount, agreement of integrated IWC with the Robust probe suggests that this may not be a great amount. We might expect a greater mass contribution from unsampled larger particles at lower elevations than sampled during this flight.

The most striking feature of the median size distributions shown is the consistent peak in particle mass at $D_{\text {eq }}$ of roughly $250 \mu \mathrm{m}$ in Fig. 4. Although the peak is narrower at higher IWC, the time series in Fig. 5 show that calculated $\mathrm{MMD}_{\mathrm{eq}}$ scarcely deviates from 200 to $300 \mu \mathrm{m}$ over
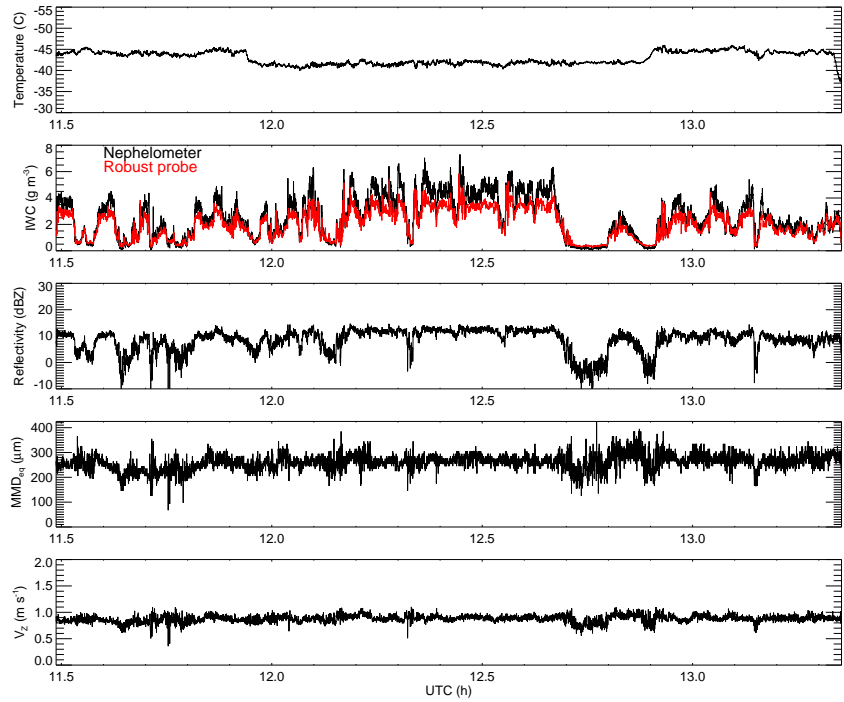

Figure 5. Static air temperature, ice water content (IWC), equivalent radar reflectivity $\left(Z_{\mathrm{e}}\right)$, ice mass median area-equivalent diameter $\left(\mathrm{MMD}_{\mathrm{eq}}\right)$, and $Z_{\mathrm{e}}$-weighted fall speed $\left(V_{Z}\right)$ during Cayenne flight F1423.

more than an order of magnitude variability in IWC. Figure 6 further demonstrates that when the calculated mass size distributions are averaged within the three mass ranges shown in Fig. $4\left(1-2,2-4\right.$, and greater than $\left.4 \mathrm{~g} \mathrm{~m}^{-3}\right)$ and then normalized by their total mass for Flight 1423, they appear roughly self-similar insofar as they exhibit similar width and shape across roughly a factor of 4 in mass concentration. Three other flights with the highest IWC encountered in each flight test location show similar behavior, with calculated $\mathrm{MMD}_{\mathrm{eq}}$ similar to $250 \mu \mathrm{m}$, although more smaller and larger particles appear likely to have been present in the Santiago flight, which sampled lower elevations (see Fig. 2); owing also to the likelihood that unsampled larger particles contributed more substantially to that flight, Santiago results are omitted from Part 2 of this study. Although Robust probe data are available at warmer temperatures (see Fig. 2), we note that Cayenne and Darwin size distributions are available only for flight legs at temperatures colder than $-40^{\circ} \mathrm{C}$ (e.g., Fig. 5), aside from several short segments of flight 1422 reaching $-33{ }^{\circ} \mathrm{C}$, which are not qualitatively different.

Within any single flight through dense anvil at circa $11 \mathrm{~km}$ altitude in the Cayenne and Darwin flights, a stable selfsimilarity of mass size distributions over a wide range of IWC can be considered a surprising result because it is generally thought that the process of ice outflow from convective updrafts and subsequent sedimentation consistently leads to preferentially larger particles and more mass occurring closer to updraft sources (e.g., Lawson et al., 1998, 2010). Consistent with that reasoning, McFarquhar and Heymsfield (1996) reported that larger ice crystals were found preferentially closer to convective cores and lower in the anvil, consis- 

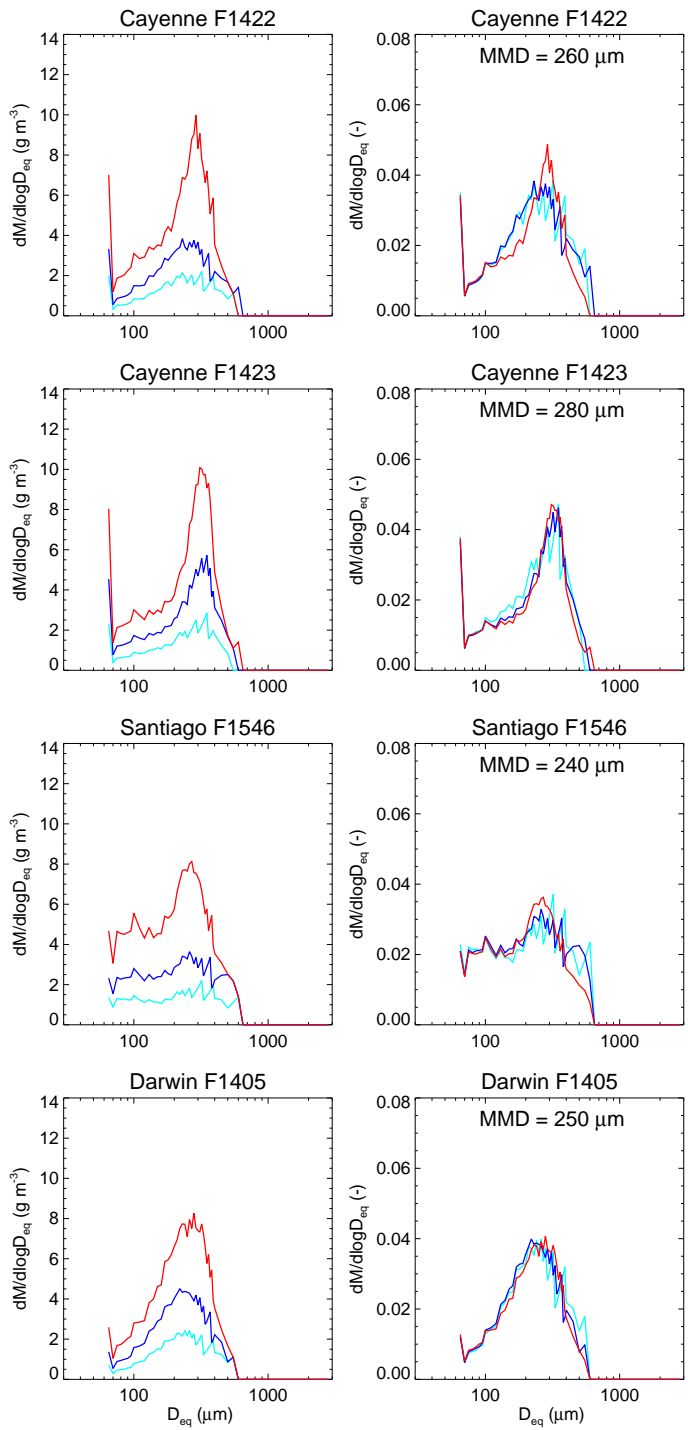

Figure 6. Ice mass size distributions in three ice water content (IWC) ranges (1-2, 2-4 and $>4 \mathrm{~g} \mathrm{~m}^{-3}$ shown in cyan, blue and red, respectively) based on bin-wise median measurements during four flights. Mass concentrations in $\mathrm{g} \mathrm{m}^{-3}$ (left panels) and normalized by IWC (right panels). Mass median area-equivalent diameter $\left(\mathrm{MMD}_{\mathrm{eq}}\right)$ listed for the highest concentration range $\left(>4 \mathrm{~g} \mathrm{~m}^{-3}\right)$.

tent with size sorting documented by Garrett et al. (2005) within Florida anvils. However, horizontal regions of relatively uniform $\mathrm{MMD}_{\max }$ were also noted in all three of the CEPEX anvils examined by McFarquhar and Heymsfield (1996), leading the authors to conclude that size sorting must not be the only dominant process in the CEPEX anvils they examined. A later study of precipitating deep convection spanning several field campaigns also reported that exponential fits to ice size distributions exhibited order-of-magnitude variability in intercept but little in slope within individual spiral loops of 5-10 km diameter (Heymsfield et al., 2002).
Encountering a consistency of $\mathrm{MMD}_{\mathrm{eq}}$ in the densest anvil clouds in different parts of the world may also be surprising given the relatively wide range of updraft strengths expected (e.g., Varble et al., 2015). One possible explanation is that the Airbus flight tests systematically targeted central regions of the largest and coldest-topped clouds in all locations (in some cases very shortly after electrical activity ceased), and that the coupled dynamical and microphysical processes that lead to the highest IWC in such clouds do so consistently by producing a concentration of mass at $\mathrm{MMD}_{\mathrm{eq}}$ of roughly $250 \mu \mathrm{m}$. Lawson et al. (2010) also reported a consistent concentration of mass in the $100-400 \mu \mathrm{m} D_{\max }$ range in both fresh and aged anvils around Central America and West Africa; a particularly stable peak of mass in that size range was also observed within turrets, leading them to suggest a microphysical pathway of ice formation in updrafts that could explain such a pattern. The size range of mass concentration found during the Airbus flight tests is also roughly consistent with that reported from CEPEX, although IWC was substantially less throughout previous scientific campaigns, even within graupel-containing updraft turrets sampled. Leroy et al. (2015) more recently report $\mathrm{MMD}_{\mathrm{eq}}$ typically $250-500 \mu \mathrm{m}$ and weakly decreasing with increasing IWC over $0.5-3 \mathrm{~g} \mathrm{~m}^{-3}$ at $-36^{\circ} \mathrm{C}$ in a system extensively sampled near Darwin during the recent High Altitude Ice Crystals/High Ice Water Content campaign, but similar measurements in another system yielding a typical $\mathrm{MMD}_{\mathrm{eq}}$ of $400-600 \mu \mathrm{m}$ instead weakly increasing with IWC. Aside, we note that shattering artifacts that may contaminate airborne probe measurements are relatively reduced for higher-order moments of the size distribution such as mass (Korolev et al., 2013a; Jackson and McFarquhar, 2014). Since the Korolev et al. (2013a) study was performed for probes with different inlet configurations, we expect that general conclusion can be extended to the Airbus nephelometer. It has been found that size-distribution measures such as $\mathrm{MMD}_{\max }$ may be subject to roughly $20 \%$ uncertainty owing to shattering artifacts, for instance (Jackson and McFarquhar, 2014).

\section{Profiling radar measurements}

Owing to the uniqueness of the Airbus flight test data, it is desirable to corroborate it somehow with independent measurements. It is also desirable to make use of remote-sensing data if possible, in part because they commonly offer the advantage of better spatiotemporal coverage than in situ flight legs, and in part because they are free of the various limitations associated with in situ probes and measurement techniques. Satellite infrared images can offer instantaneous storm wide coverage, for instance, but include no direct information on either IWC or $Z_{\mathrm{e}}$ within dense anvil regions. Groundbased scanning weather radars can offer storm wide $Z_{\mathrm{e}}$ measurements at relevant volumetric resolutions of $O\left(1 \mathrm{~km}^{3}\right)$, but variability in ice hydrometeor single-crystal and size- 
distribution properties preclude reliable retrievals of IWC at this time. Vertically pointing radars can also provide nonattenuated $Z_{\mathrm{e}}$ at relevant volumetric scales of $O\left(100 \mathrm{~m}^{3}\right)$, in addition to mean Doppler velocity (MDV). Since MDV represents a higher order moment of the ice size distribution than $Z_{\mathrm{e}}$, it provides the valuable benefit of an independent measurement constraint that is also sensitive to mass size distribution. Here we will focus on extended stratiform regions where the mean contribution of vertical winds to MDV can be neglected relative to the reflectivity-weighted fall speed of ice at elevations circa $11 \mathrm{~km}$. The chief disadvantage of profiling radars is the severely reduced spatial coverage of a profile compared with a scanning radar volume. However, on 23 January 2006 during the TWP-ICE campaign, the NOAA S-band profiler obtained a time series of measurements during evolution of a tropical MCS near Darwin (Fig. 7). The remainder of this work is devoted to examination of these measurements in comparison with the Airbus flight test data.

The S-band MDV curtain in Fig. 8 shows two broad periods of stratiform rain passing over the profiler on 23 January 2006, bisected by a several-hour period of intermittent turbulence throughout the observed column at roughly $23.65-$ 23.83. The stratiform periods are characterized by a sharp decrease in MDV at the melting-level height of roughly $5 \mathrm{~km}$, where melting ice also creates a bright band in $Z_{\mathrm{e}}$ as the meltwater undergoes conversion to faster-falling rain. During the turbulent convective period, Doppler velocities reach localized peaks of nearly $10 \mathrm{~m} \mathrm{~s}^{-1}$ upward and exceeding $10 \mathrm{~m} \mathrm{~s}^{-1}$ downward. The strongest drafts are co-located with the strongest deep echoes observed in the storm above $15 \mathrm{~km}$. Where a bright band is present, owing to the melting of ice into stratiform rain, $Z_{\mathrm{e}}$ in excess of $10 \mathrm{dBZ}$ commonly still extends above $11 \mathrm{~km}$, with some detectable echoes extending above $15 \mathrm{~km}$. Below the bright band, heavy rain is indicated by $Z_{\mathrm{e}}$ in excess of $30 \mathrm{dBZ}$.

Figure 9 shows time series extracted from the S-band profiles and surface rain rate measured by a co-located NOAA Joss Waldvogel disdrometer. Reflectivity, MDV, and Doppler spectral width are shown at an elevation of $11.7 \mathrm{~km}$, where soundings available from Darwin on 23 January indicate a temperature of $-43^{\circ} \mathrm{C}$, close to that during Cayenne flight F1423. Although $Z_{\mathrm{e}}$ at this elevation nears $30 \mathrm{dBZ}$ (during convective periods), it does not exceed that. The two stratiform time periods within dashed lines are the contiguous periods of at least $15 \mathrm{~min}$ where, at $11.7 \mathrm{~km}, Z_{\mathrm{e}}$ is greater than $5 \mathrm{dBZ}, \mathrm{MDV}$ is $0-2 \mathrm{~m} \mathrm{~s}^{-1}$, and Doppler spectral width is less than $2.5 \mathrm{~m} \mathrm{~s}^{-1}$. At $4.7 \mathrm{~km}, Z_{\mathrm{e}}$ is greater than $25 \mathrm{dBZ}$. The beginning of the first period (12:17-14:07 UTC) corresponds to the earliest panel in Fig. 7 and the end of the second period (20:13-21:49 UTC) to the last panel. Also shown in Fig. 9 are retrievals of vertical wind speed obtained from the profilers at the highest elevation where retrievals were usually possible $(9 \mathrm{~km})$ and near-surface rain rate where retrievals can confidently be made $(2.5 \mathrm{~km})$ (Williams and May, 2008; Williams and Gage, 2009). Retrieved vertical winds and S-band spec-
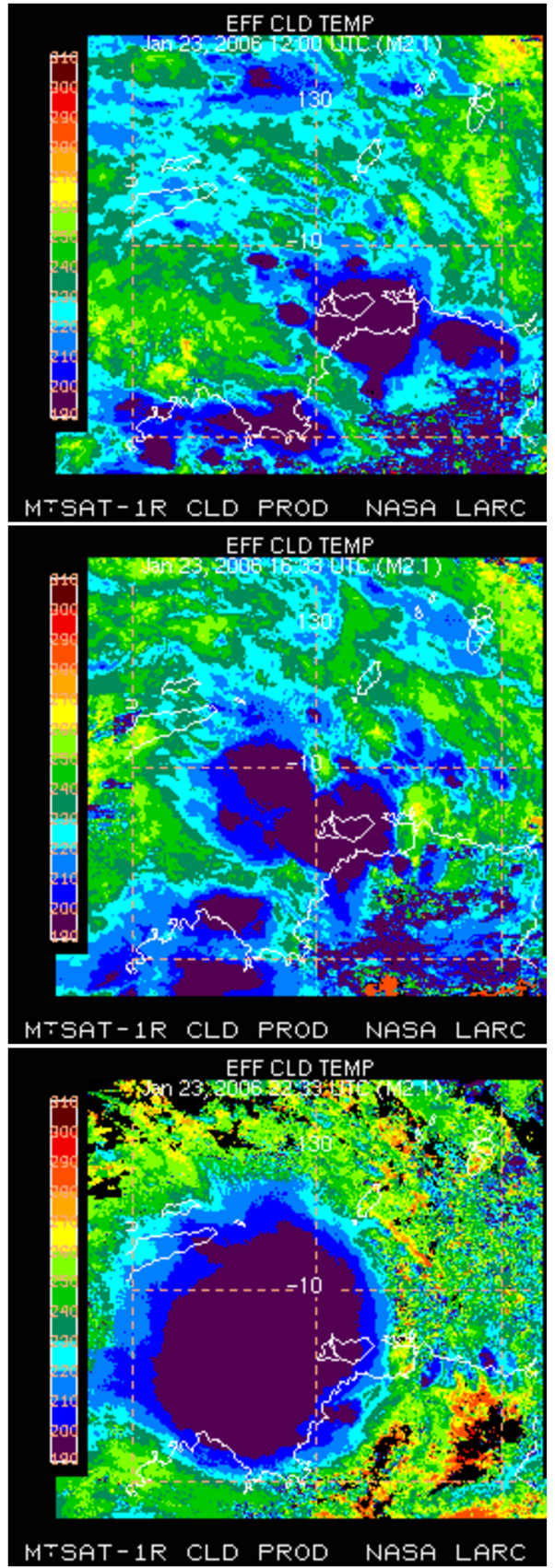

Figure 7. Cloud top temperature derived from MTSAT-1R at 12:00, 16:33, and 22:33 UTC on 23 January 2006 over Darwin. The darkest shade is colder than $200 \mathrm{~K}$, overlying a region that includes the Tiwi Islands in each image.

tral width indicate that the two stratiform periods are quiescent, with minimal turbulence and no strong updrafts. During each period, maximum $Z_{\mathrm{e}}$ below the melting level exceeds $40 \mathrm{dBZ}$ and maximum rain rate retrieved at $2.5 \mathrm{~km}$ reaches nearly $4 \mathrm{~mm} \mathrm{~h}^{-1}$. At the surface, rain rates measured by disdrometer tend to read sustained peaks circa $2-4 \mathrm{mh}^{-1}$ near 

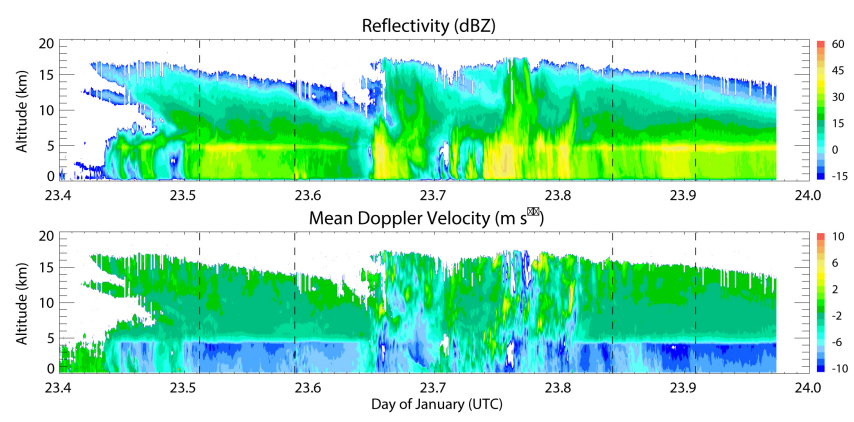

Figure 8. Equivalent radar reflectivity $\left(Z_{\mathrm{e}}\right)$ and mean Doppler velocity curtain measured by the S-band profiler on 23 January 2006. Dashed lines indicate duration of two stratiform rain periods defined as described in text.

the midpoints of the stratiform periods rather than at the endpoints.

Figure 10 shows MDV vs. $Z_{\mathrm{e}}$ in linear coordinates during each stratiform period. Mean values of MDV indicate $Z_{\mathrm{e}^{-}}$ weighted fall speeds of roughly $1 \mathrm{~m} \mathrm{~s}^{-1}$ during each period, consistent with those calculated from Cayenne flight F1423 measurements (Fig. 5) using the method of Heymsfield and Westbrook (2010). In the profiler data, coherent oscillations in retrieved vertical winds at $9 \mathrm{~km}$ and in MDV at $11.7 \mathrm{~km}$ are likely indicative of gravity waves, and these generate a significant component of scatter around the mean in Fig. 10; extraction of gravity waves is considered beyond the scope of this work. Although it is difficult to draw conclusions owing to lack of retrieved winds at $11 \mathrm{~km}$, it appears possible that MDV may be a weak function of $Z_{\mathrm{e}}$, as suggested by MDV calculated from the Airbus data, as expected in the case that size distributions are not strongly dependent on IWC. During the second period in Fig. 10, fall speeds do appear faster where reflectivity exceeds $20-30 \mathrm{~mm}^{6} \mathrm{~m}^{-3}$; omission of the full $Z_{\mathrm{e}}$ spectrum apparent in the Airbus measurements, as discussed above, may substantially truncate the contribution of the largest particles to MDV in the Airbus data.

Overall, the S-band measurements and retrievals appear to generally confirm that regions of low- $Z_{\mathrm{e}}$ can be associated with relatively stable MDV of circa $1 \mathrm{~m} \mathrm{~s}^{-1}$ under conditions similar to those sampled on flight F1423. MDV, which includes air motions, does not vary strongly with a factor of 4 change in $Z_{\mathrm{e}}$ in these regions, consistent with rough self-similarity in size-distribution shape found in the in situ Airbus measurements. Figure 9 shows that $Z_{\mathrm{e}}$ frequently exceeds $30 \mathrm{dBZ}$ below these stratiform regions, consistent with high- $Z_{\mathrm{e}}$ conditions beneath low- $Z_{\mathrm{e}}$ legs aloft. Co-located retrievals of rain rate indicate precipitation exceeding $3 \mathrm{~mm} \mathrm{~h}^{-1}$, consistent with heavy rain expected beneath high IWC conditions.
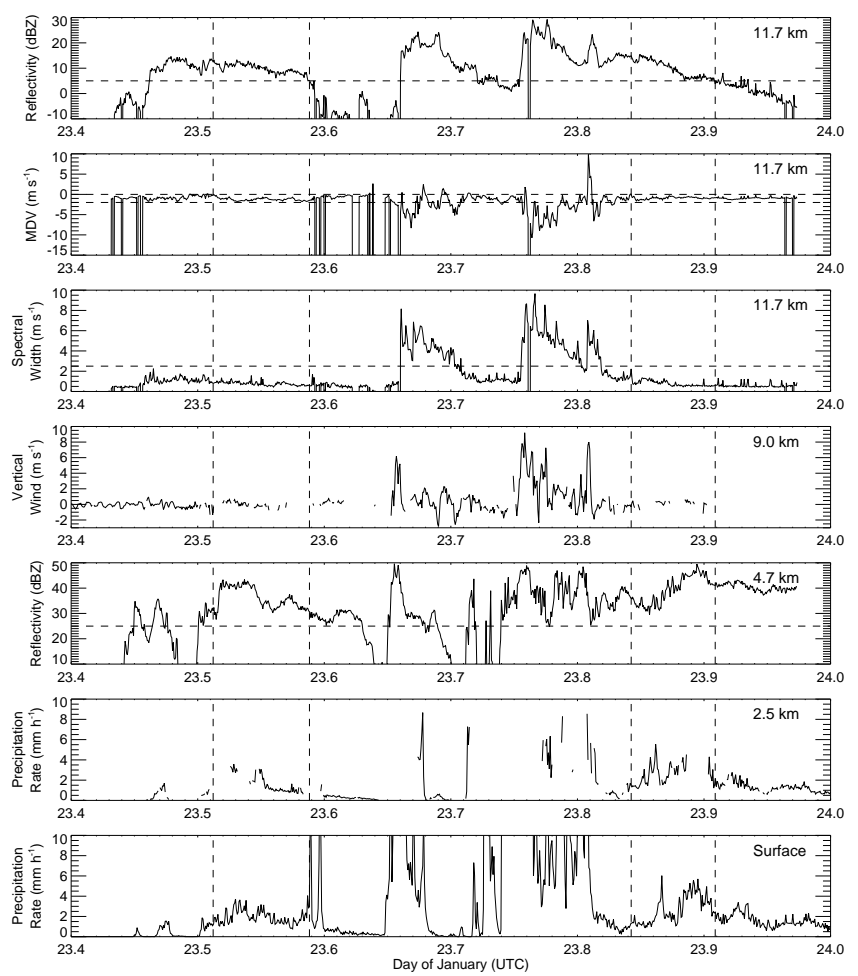

Figure 9. Time series of observations and retrievals from co-located S-band, UHF, and VHF profilers on 23 January 2006: radar reflectivity $\left(Z_{\mathrm{e}}\right)$, mean Doppler velocity (MDV; negative downward), and Doppler velocity spectral width at $11.7 \mathrm{~km}$; retrieved vertical wind speed at $9 \mathrm{~km} ; Z_{\mathrm{e}}$ just below the melting level at $4.7 \mathrm{~km}$; retrieved precipitation rate at $2.5 \mathrm{~km}$; and precipitation rate measured at the surface. Vertical dashed lines indicate stratiform rain periods as in Fig. 8.
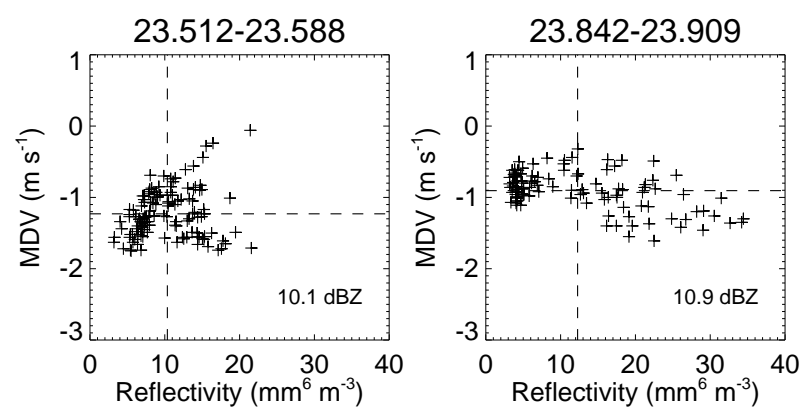

Figure 10. Mean Doppler velocity vs. equivalent radar reflectivity measured by S-band profiler during two stratiform periods shown in Figs. 8 and 9. Dashed lines indicate mean values within each sample; mean reflectivity reported in $\mathrm{dBZ}$ units at lower left.

\section{Column model simulations}

As shown above, the ice size-distribution features found in Airbus flight tests are found to be generally consistent with other recent in situ measurements in the vicinity of deep convection and with profiling radar measurements in a large 
tropical MCS. Here we take a step further to compare onedimensional simulations of the quasi-steady stratiform rain regions observed during TWP-ICE with the profiling radar observations. This comparison is intended to allow for an evaluation of whether the ice mixing ratios measured in high IWC regions are consistent with heavy rain rates retrieved below, for instance. As shown in Part 2, three-dimensional simulations generally fail to reproduce the observed ice sizedistribution features in deep convection, with concentration of mass narrowly in the $100-500 \mu \mathrm{m} D_{\max }$ range at temperatures below $-40^{\circ} \mathrm{C}$. This exercise therefore also serves to test how well a column simulation with size-resolved microphysics can perform when initialized with the observed size distributions and an observation-based estimate of binwise ice properties, and when limited to the relatively simple dominant processes of sedimentation and aggregation in the stratiform region.

We begin with an atmospheric column with $250 \mathrm{~m}$ vertical grid spacing that is initialized thermodynamically with a mean of soundings observed around at Darwin at 21:00 UTC on 23 January 2006, obtained from a variational analysis of conditions over the TWP-ICE sounding array (Xie et al., 2010). This time is selected to be representative of high- $Z_{\mathrm{e}}$, heavy stratiform rain indicated in Figs. 8 and 9. Furthermore, we note that no sounding is available at Darwin during the second half of 23 January owing to balloon failures. The atmospheric column is saturated with respect to ice at relevant elevations above $8 \mathrm{~km}$. At the melting-level relative humidity is roughly $90 \%$, increasing above and below with respect to ice and water, respectively (not shown).

We initialize the column with Airbus ice size-distribution measurements obtained over Darwin during flight F1405. The mass size distributions averaged over regions with reported IWC greater than $4 \mathrm{~g} \mathrm{~m}^{-3}$ shown in Fig. 6 represent a mean IWC of $4.3 \mathrm{~g} \mathrm{~m}^{-3}$ measured between 11 and $11.5 \mathrm{~km}$. The calculated $Z_{\mathrm{e}}$ and MDV are shown with blue asterisks in Fig. 11. Here we assume that the particles have the mass and $D_{\text {eq }}$ that were shown to agree with the Robust probe measurements. For simplicity, we assume that the ice particles are spherical in shape. Given mass and $D_{\text {eq }}$, we therefore assume that $D_{\max }$ is equal to $D_{\text {eq }}$, the projected area is related to $D_{\text {eq }}$ by definition, and the overall particle aspect ratio is unity. Particle fall speeds and pair-wise collision efficiencies are calculated following Böhm (1999), with fall speeds modified following Heymsfield and Westbrook (2010) as described by Avramov et al. (2011).

For these simulations, we adopt a steady-state simulation approach, considering that large and long-lived stratiform regions are changing slowly over hours in time, therefore exhibiting roughly equal quantities of mass coming from above and exiting below at each level. We neglect large-scale vertical motion. To speed up simulation time to steady state, we initialize all elevations above the melting level with the same observed mass size distribution. Vapor exchange with hydrometeors is permitted to represent evaporation of ice
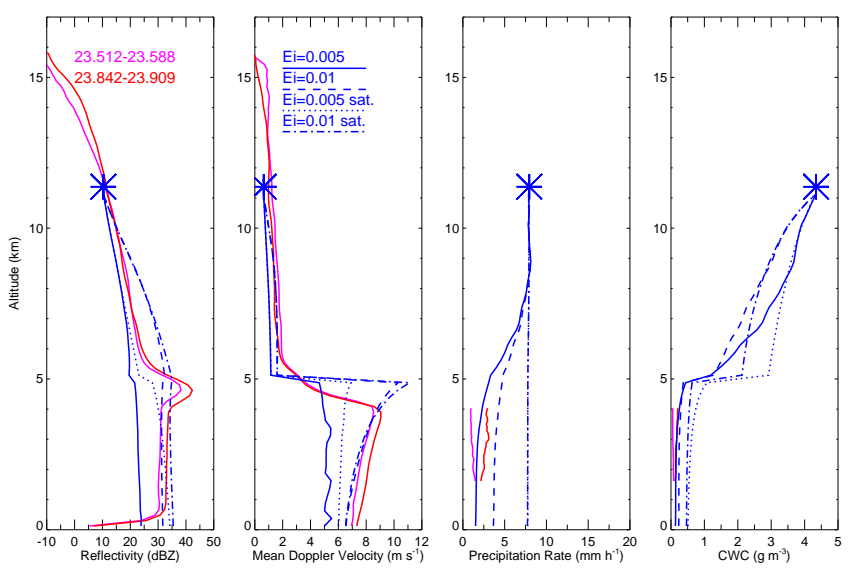

Figure 11. Profiles of reflectivity, mean Doppler velocity (positive downward), precipitation rate (liquid equivalent), and condensed water content (CWC) observed by the S-band profiler or retrieved from S-band, UHF, and VHF radars during the stratiform periods identified in Fig. 8 (pink and red) are compared with steady-state column model results initialized with size distributions measured during Airbus test flights at 11-11.5 km over Darwin (blue). Simulations use ice-ice sticking efficiencies of 0.01 or 0.005 , and the baseline sounding or a saturated sounding (see text).

and liquid in the unsaturated regions, treated as described in Fridlind et al. (2012b) and discussed further in Part 2. However, we fix temperatures and water vapor mixing ratios to the observed profile, thereby neglecting cooling at the melting level, which would otherwise require application of divergence terms to remain stable as observed. Melting of ice is treated in a rudimentary fashion, by transferring all ice to melted equivalent drops when the column temperature allows.

In Fig. 11 simulated $Z_{\mathrm{e}}$, Doppler velocity, precipitation rate, and CWC (liquid plus ice) are shown for two values of ice-ice sticking efficiency ( 0.01 and 0.005$)$ and two environmental conditions (the observed sounding or a saturated version) after reaching steady state. Also shown are profiles measured by the S-band profiler $\left(Z_{\mathrm{e}}\right.$ and $\left.\mathrm{MDV}\right)$ or retrieved with a combination of S-band, UHF, and VHF data below the melting level (rain rate and CWC). The observed and retrieved data at each elevation represent means of the available values over the stratiform time periods shown in Figs. 8 and 9. At the top of the simulated columns, $Z_{\mathrm{e}}$ and MDV represent the steady-state boundary condition. As the ice aggregates during sedimentation, the $Z_{\mathrm{e}}$ monotonically increases. In the simulations, the rate of increase scales with the sticking efficiency $\left(E_{i}\right)$, defined here as the probability that an ice-ice collision results in aggregation. The probability is taken here to be fixed, although it may be a substantial function of environmental conditions and ice morphological properties in a manner that is not generally well established observationally (e.g., Kienast-Sjögren et al., 2013, and references therein). Owing to the omission of mixed-phase parti- 
cles from this simplified model, ice instantly melts when the temperature is warm enough, and simulations therefore do not reproduce the melting band feature in $Z_{\mathrm{e}}$ or the smooth increase in MDV seen in the observations.

MDV above the melting level is usually similar to observed or is underestimated by a few tenths of a meter per second. MDV below the melting level is similar to observed when $Z_{\mathrm{e}}$ is similar to observed, including reproducing a reduction of MDV with distance towards the surface, except in one simulation with a saturated sounding, indicating that evaporation may substantially increase MDV. However, underestimation of MDV below the melting level in a simulation could also be attributable to missing mixed-phase processes (e.g., Phillips et al., 2007), which could enhance aggregation.

Simulations are shown using an observed sounding (with $\mathrm{RH}$ of roughly $90 \%$ at the melting level, as described above) and with the same sounding that has been saturated with respect to ice and water above and below the melting level, respectively. Simulations with the saturated sounding demonstrate that in a steady-state environment without evaporation, precipitation rate is constant with height. Thus, an IWC of $4 \mathrm{~g} \mathrm{~m}^{-3}$ introduced at $11 \mathrm{~km}$, with the ice morphological and size-distribution properties consistent with Airbus measurements, corresponds to a rain rate of roughly $8 \mathrm{~mm} \mathrm{~h}^{-1}$ under saturated conditions. Figure 12 shows that half as much IWC aloft, without a change in ice size distribution or properties, corresponds to roughly $4 \mathrm{~mm} \mathrm{~h}^{-1}$ throughout a saturated column.

Unlike the constant precipitation rate profile in a saturated column at steady state, the simulated CWC profile decreases monotonically and drastically between $11 \mathrm{~km}$ and the surface. Most dramatically, melting ice causes a rapid increase in fall speed (consistent with observed MDV), which is accompanied by a rapid decrease in CWC to maintain a uniform (steady-state) precipitation rate. Above the melting level, IWC undergoes a more gentle decrease during sedimentation; simulations that roughly reproduce the trend in $Z_{\mathrm{e}}$ with height above the melting level also exhibit a roughly $30-50 \%$ decrease in IWC between 11 and $5 \mathrm{~km}$. Thus, aggregation consistent with increasing $Z_{\mathrm{e}}$ corresponds to a reduction of IWC as ice sediments faster.

\section{Meteorological context}

The Australian Bureau of Meteorology $C$ band scanning polarimetric radar at Darwin (C-POL; Keenan et al., 1998) offers a wider view of rain rates, which are retrieved at $2.5 \mathrm{~km}$ in altitude following Bringi et al. (2001), and a threedimensional view of hydrometeor class aloft (Keenan, 2003; May and Keenan, 2005). Of the two quiescent stratiform periods identified in Fig. 8, the second turns out to be far more extensive horizontally, with higher peak rain rates seen by disdrometer (Fig. 9). Figure 13 shows $2.5 \mathrm{~km}$ cross sec-
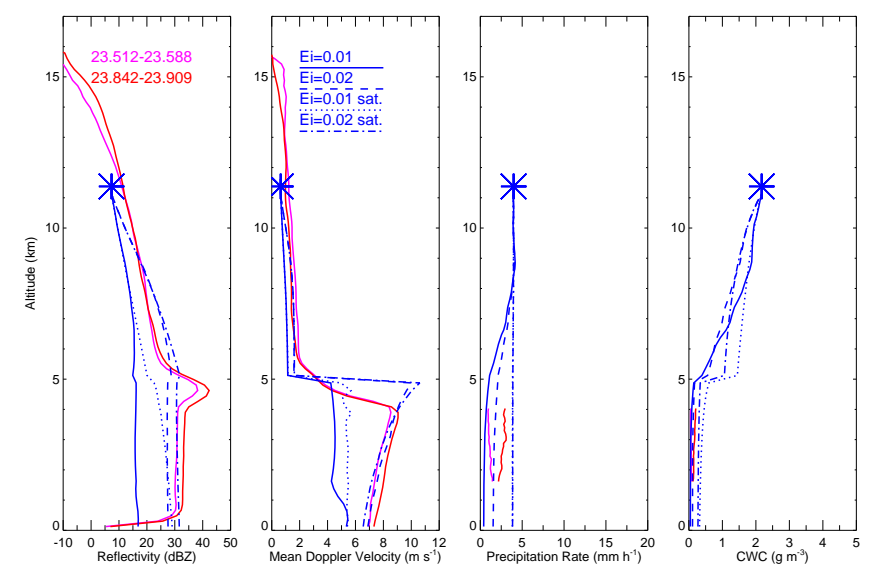

Figure 12. Same as Fig. 11 except that the initial ice size distribution is scaled by a factor of 0.5 .

tions of $Z_{\mathrm{e}}$ and rain rate from C-POL measurements near the time of maximum stratiform rain rate at the S-band profiler, whose location is indicated with an asterisk. Areas outlined in black are those identified as convective using the Steiner et al. (1995) textural algorithm as in Fridlind et al. (2012a); surrounding areas are classified as stratiform. At the time shown, the S-band is embedded within an extensive stratiform area where most rain rates are $2-4 \mathrm{~mm} \mathrm{~h}^{-1}$, although higher rain rates of $4-8 \mathrm{~mm} \mathrm{~h}^{-1}$ can be found locally roughly $50 \mathrm{~km}$ northwest of the profiler. Thus, maximum stratiform rain rates in these observations appear roughly consistent with the maximum measured IWC aloft, sedimenting under saturated conditions, in our calculations, but such rain rates are not widespread. The locally stronger stratiform rain rates could also be attributable to enhanced precipitation from mesoscale ascent concentrated at lower elevations or other processes that could enhance rain rate locally by other means, rather than high IWC far aloft.

Although convective rain areas that contain some amount of hail are found north and south of the stratiform rain area over the S-band in Fig. 13, $Z_{\mathrm{e}}$ does not exceed $30 \mathrm{dBZ}$ at $11 \mathrm{~km}$ anywhere within the C-POL domain at that time. Figure 14 shows the C-POL fields at the time of the strongest convective rain over the S-band, by contrast. Here the Sband is now embedded within a linear band of convection containing a continuous elongated region with some amount of hail according to C-POL definitions. However, at $11 \mathrm{~km}$ there remain only several tiny areas of $30 \mathrm{dBZ} Z_{\mathrm{e}}$; these areas are periodically slightly larger during some periods earlier and later, but are never extensive during this event (not shown). Vertical wind speeds retrieved at $9 \mathrm{~km}$ from the profilers reach $4-10 \mathrm{~m} \mathrm{~s}^{-1}$ during roughly an hour-long period containing convective cells over the S-band, including the time of Fig. 14. These would presumably be associated with moderate turbulence. 

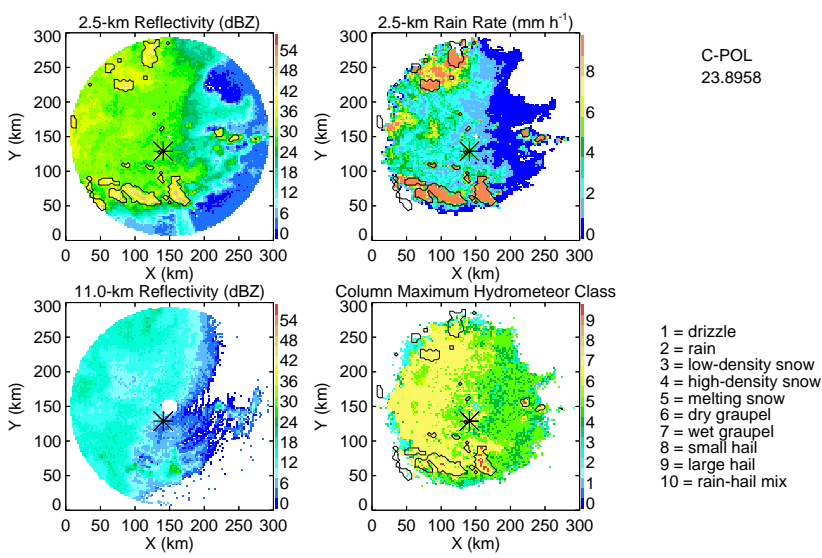

Figure 13. Cross sections from C-POL radar fields when the Sband experienced stratiform rain at 23.8958 (cf. Fig. 8): $Z_{\mathrm{e}}$ and rain rate at $2.5 \mathrm{~km}$ altitude, $Z_{\mathrm{e}}$ at $11 \mathrm{~km}$ altitude, and column maximum hydrometeor class (see legend). The location of the S-band profiler is marked with an asterisk. Areas outlined in black are identified as convective (see text) except in the $11 \mathrm{~km} Z_{\mathrm{e}}$ field, where they enclose areas greater than $30 \mathrm{dBZ}$ (only present in Fig. 14).

Separation of rainy areas into convective and stratiform areas has an origin in the first-order division of mid-latitude squall lines into ice particle source regions, where vertical winds commonly exceed ice crystal fall speeds (thus transporting particles to detrainment regions), and ice particle sink regions dominated by ice particle sedimentation (Biggerstaff and Houze, 1991). Subsequent analyses usefully extended this framework to consideration of tropical storms, the differing properties of convective and stratiform region energy and water budgets, and their unique consequences for atmospheric circulation (e.g., Houze, 2004; Schumacher et al., 2004; Zeng et al., 2013). However, the structure of convective regions within a tropical MCS present a large variety (Mapes and Houze, 1992, cf. their Fig. 15). In the system studied here, convection is sometimes organized into linear features, but individual convective turrets are also commonly scattered within regions identified as stratiform, consistent with otherwise quiescent vertical winds and low rain rates.

\section{Conclusions}

Roughly 100 well-documented jet engine power loss and damage events described in the literature to date have been characterized by high IWC-low- $Z_{\mathrm{e}}$ conditions encountered almost exclusively in the vicinity of deep convection under conditions of weak to moderate turbulence. During 2010 2012 Airbus flight tests from Cayenne, Darwin, and Santiago carried a new SEA Robust hot-wire probe and an imaging nephelometer used to report ice particle size distributions. A chief objective of the flight tests was to find and remain within the highest IWC regions, within the limits of safety, in a manner similar to that described by McNaughton (1959).
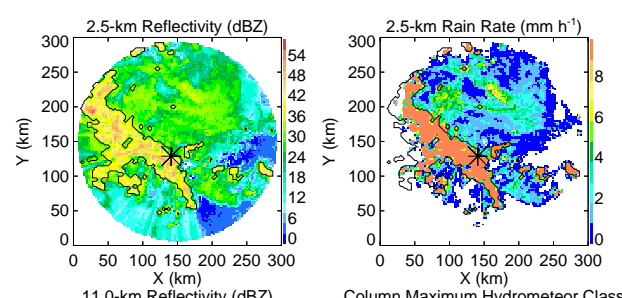

$$
\begin{aligned}
& \text { C-POL } \\
& 23.7639
\end{aligned}
$$
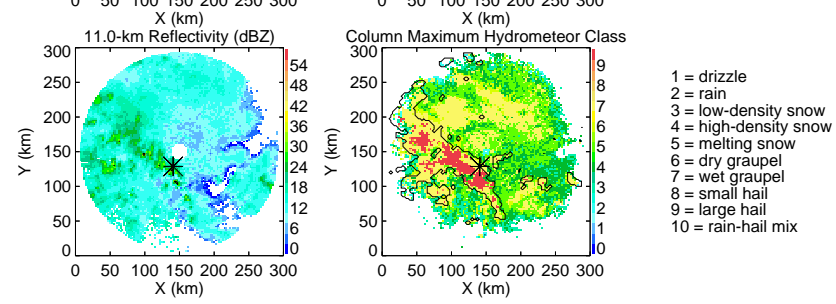

Figure 14. Same as Fig. 13 except when the S-band experienced convective rain at 23.7639 .

Whereas that earlier study measured CWC at 0 to $-26^{\circ} \mathrm{C}$, the Airbus flights primarily sampled at colder temperatures, where many such events have occurred (cf. Grzych and Mason, 2010).

Similar to CWC measurements reported by McNaughton (1959), IWC measurements of roughly $2 \mathrm{~g} \mathrm{~m}^{-3}$ were not rare at any of the three global regions sampled, and maximum IWC exceeded twice that value at $10 \mathrm{~km}$ length scales (see also Grandin et al., 2014). These IWC measurements are roughly a factor of 2 greater than measurements from similar cloud regions documented in the scientific literature to date. However, as noted above, a large database of such measurements is not yet available. In addition, the factor-of- 2 uncertainty generally assigned to IWC measurements by any means, in the absence of past test facilities to provide ground truth (Strapp et al., 2008; Baumgardner et al., 2011), could also account for some of the difference across various direct and indirect measurement approaches.

An examination of the Airbus nephelometer data in the regions of the highest IWC at elevations circa $10 \mathrm{~km}$ indicate that mass size distributions were dominated by particles in the $100-500 \mu \mathrm{m}$ range of area-equivalent diameter consistently across all locations. The mass size distributions also consistently exhibited an unexpected self-similarity, or stability of shape, over large changes in IWC. Calculations of $Z_{\mathrm{e}}$ size distributions from the nephelometer data as shown in Fig. 4 make apparent that the largest particles present were not measured by the nephelometer (limited to $D_{\max }$ nominally smaller than $2-3 \mathrm{~mm}$ ), perhaps unrealistically enhancing the stability of mass median diameter over the size range seen. On the other hand, similar features have also been reported in previous data sets and analyses.

Owing to the great uncertainty associated with both IWC and size-distribution measurements, here we describe a comparison of the measurements with ground-based profiling radar measurements that offer two independent measurements sensitive to ice morphological and size-distribution 
properties over the full atmospheric column observed: $Z_{\mathrm{e}}$ and MDV. We focus on regions of heavy stratiform rain within an MCS observed with remote-sensing instruments over Darwin on 23 January 2006, where large-scale vertical motions are neglected to first order compared with reflectivity-weighted ice fall speeds. During heavy stratiform rain periods, $Z_{\mathrm{e}}$ is less than $30 \mathrm{dBZ}$ at typical Airbus sampling elevations of $11 \mathrm{~km}$ and MDV is found to be roughly $1 \mathrm{~m} \mathrm{~s}^{-1}$, consistent with that calculated from Airbus flight test data. MDV appears relatively weakly correlated with $Z_{\mathrm{e}}$ at $11 \mathrm{~km}$, which is consistent with self-similar ice size distributions. However, gravity waves with periods of perhaps one-half of the stratiform rain duration appear present in vertical wind speed retrievals available up to $9 \mathrm{~km}$, complicating analysis of MDV relationship to $Z_{\mathrm{e}}$.

Column model simulations initialized with ice morphological and particle size distributions consistent with Airbus Robust probe and nephelometer measurements are intended to test whether the properties of a steady-state stratiform rain column under conditions of heavy precipitation appears consistent with the measurements. If the column is assumed saturated with respect to ice and water above and below the melting level, then the precipitation rate is independent of height, and an IWC of $4 \mathrm{~g} \mathrm{~m}^{-3}$ is found to correspond to a rain rate of roughly $8 \mathrm{mmh}^{-1}$. This is roughly twice the maximum rain rate observed by disdrometer or retrieved at $2.5 \mathrm{~km}$ in the 23 January event, but polarimetric retrievals of rain rate around the profiler did report such rates locally within the stratiform region. It is unknown whether such locally enhanced rain rates can be attributed to ice aloft or some mesoscale ascent, which seems equally possible. Model simulations also indicate that in a column that is $10 \%$ undersaturated in the vicinity of the melting level, precipitation can be rapidly reduced by evaporation. Finally, steady-state simulations with aggregation sufficient to explain increasing $Z_{\mathrm{e}}$ with decreasing elevation owing to aggregation alone also exhibit roughly $30-50 \%$ reduced IWC by the melting level owing to increasing mass-weighted fall speed. Thus, in a steady-state column under such conditions, IWC is expected to be higher aloft than at the melting level. In summary, the highest Airbus IWC measurements near Darwin do appear grossly consistent with the highest stratiform rain rates and ice properties observed during the 23 January 2006 event over Darwin.

The objective of Part 1 of this two-part study has been to vet the Airbus size-distribution measurements to the degree possible in comparison with past measurements and a uniquely relevant remote-sensing data set. A simplified modeling framework served to extend the comparison by relating IWC aloft with rain rates below. Given a lack of gross inconsistencies, here we conclude that size distribution and IWC measurements appear to give a reasonable representation of high IWC-low- $Z_{\mathrm{e}}$ ice properties, albeit with large uncertainties. The objective of Part 2 is to examine micro- physical pathways by which such properties could likely be achieved under relevant updraft conditions.

Acknowledgements. TWP-ICE soundings and S-band radar data were obtained from the Atmospheric Radiation Measurement (ARM) Program sponsored by the U.S. Department of Energy, Office of Science, Office of Biological and Environmental Research, Climate and Environmental Sciences Division. C-POL radar measurements and retrieval products were supplied by Peter May, Centre for Australian Weather and Climate Research, Australian Bureau of Meteorology. The authors thank Thomas Ratvasky and Ron Colantonio for logistical and programmatic assistance, and Jeanne Mason and Matthew Grzych for valuable discussion. This work was supported by the NASA Aviation Safety Program's Atmospheric Environment Safety Technologies Project. We thank Airbus for providing their data to support this research.

Edited by: T. Garrett

\section{References}

Ackerman, A. S., Fridlind, A. M., Grandin, A., Dezitter, F., Weber, M., Strapp, J. W., and Korolev, A. V.: High ice water content at low radar reflectivity near deep convection - Part 2: Evaluation of microphysical pathways in updraft parcel simulations, Atmos. Chem. Phys., 15, 11729-11751, doi:10.5194/acp15-11729-2015, 2015.

Avramov, A., Ackerman, A. S., Fridlind, A. M., van Diedenhoven, B., Botta, G., Aydin, K., Verlinde, J., Korolev, A. V., Strapp, J. W., McFarquhar, G. M., Jackson, R., Brooks, S. D., Glen, A., and Wolde, M.: Toward ice formation closure in Arctic mixedphase boundary layer clouds during ISDAC, J. Geophys. Res., 116, D00T08, doi:10.1029/2011JD015910, 2011.

Baker, B. and Lawson, R. P.: Improvement in determination of ice water content from two-dimensional particle imagery. Part I: Image-to-mass relationships, J. Appl. Meteorol. Clim., 45, 12821290, 2006.

Baumgardner, D., Brenguier, J.-L., Bucholtz, A., Coe, H., DeMott, P., Garrett, T. J., Gayet, J. F., Hermann, M., Heymsfield, A., Korolev, A., Krämer, M., Petzold, A., Strapp, W., Pilewskie, P., Taylor, J., Twohy, C., Wendisch, M., Bachalo, W., and Chuang, P.: Airborne instruments to measure atmospheric aerosol particles, clouds and radiation: a cook's tour of mature and emerging technology, Atmos. Res., 102, 10-29, doi:10.1016/j.atmosres.2011.06.021, 2011.

Biggerstaff, M. and Houze Jr., R. A.: Kinematic and precipitation structure of the 10-11 June 1985 squall line, Mon. Weather Rev., 119, 3034-3065, 1991.

Biggerstaff, M. and Houze Jr., R. A.: Kinematics and microphysics of the transition zone of the 10-11 June 1985 squall line, J. Atmos. Sci., 50, 3091-3091, 1993.

Böhm, J. P.: Revision and clarification of "A general hydrodynamic theory for mixed-phase microphysics", Atmos. Res., 52, 167176, 1999.

Bringi, V. N., Huang, G.-J., Chandrasekar, V., and Keenan, T.: An areal rainfall estimator using differential propagation phase: evaluation using a C-band radar and a dense gauge network in the tropics, J. Atmos. Ocean. Tech., 18, 1810-1818, 2001. 
Brown, P. R. and Francis, P. N.: Improved measurements of the ice water content in cirrus using a total-water probe, J. Atmos. Ocean. Tech., 12, 410-414, 1995.

Connolly, P. J., Saunders, C. P. R., Gallagher, M. W., Bower, K. N., Flynn, M. J., Choularton, T. W., Whiteway, J., and Lawson, R. P.: Aircraft observations of the influence of electric fields on the aggregation of ice crystals, Q. J. Roy. Meteor. Soc., 131, 16951712, doi:10.1256/qj.03.217, 2005.

Delanoë, J. M. E., Heymsfield, A. J., Protat, A., Bansemer, A., and Hogan, R. J.: Normalized particle size distribution for remote sensing application, J. Geophys. Res., 119, 1-24, doi:10.1002/2013JD020700, 2014.

Dezitter, F., Grandin, A., Brenguier, J.-L., Hervy, F., Schalger, H., Villedieu, P., and Zalamansky, G.: HAIC - High Altitude Ice Crystals, in: Fifth AIAA Atmospheric and Space Environments Conf., American Institute of Aeronautics and Astronautics, San Diego, California, USA, 24-27 June 2013, AIAA 2013-2674, 2013.

Emery, E., Miller, D., Plaskon, S., Strapp, W., and Lillie, L.: Ice particle impact on cloud water content instrumentation, in: 42nd AIAA Aerospace Sciences Meeting and Exhibit, American Institute of Aeronautics and Astronautics, Reston, Virigina, USA, 5-8 January 2004, AIAA 2004-731, 2004.

Fridlind, A. M., Ackerman, A. S., Chaboureau, J.-P., Fan, J., Grabowski, W. W., Hill, A. A., Jones, T. R., Khaiyer, M. M., Liu, G., Minnis, P., Morrison, H., Nguyen, L., Park, S., Petch, J. C., Pinty, J. P., Schumacher, C., Shipway, B. J., Varble, A. C., Wu, X., Xie, S., and Zhang, M.: A comparison of TWP-ICE observational data with cloud-resolving model results, J. Geophys. Res., 117, D05204, doi:10.1029/2011JD016595, 2012a.

Fridlind, A. M., van Diedenhoven, B., Ackerman, A. S., Avramov, A., Mrowiec, A., Morrison, H., Zuidema, P., and Shupe, M. D.: A FIRE-ACE/SHEBA case study of mixed-phase Arctic boundary layer clouds: Entrainment rate limitations on rapid primary ice nucleation processes, J. Atmos. Sci., 69, 365-389, doi:10.1175/JAS-D-11-052.1, 2012b.

Garrett, T. J., Navarro, B. C., Twohy, C. H., Jensen, E. J., Baumgardner, D. G., Bui, P. T., Gerber, H., Herman, R. L., Heymsfield, A. J., and Lawson, P.: Evolution of a Florida cirrus anvil, J. Atmos. Sci., 62, 2352-2372, doi:10.1175/JAS3495.1, 2005.

Gayet, J.-F., Shcherbakov, V., Bugliaro, L., Protat, A., Delanoë, J., Pelon, J., and Garnier, A.: Microphysical properties and high ice water content in continental and oceanic mesoscale convective systems and potential implications for commercial aircraft at flight altitude, Atmos. Chem. Phys., 14, 899-912, doi:10.5194/acp-14-899-2014, 2014.

Grandin, A., Merle, J.-M., Weber, M., Strapp, J., Protat, A., and King, P.: AIRBUS flight tests in high total water content regions, in: 6th AIAA Atmospheric and Space Environments Conference, American Institute of Aeronautics and Astronautics, Reston, Virginia, USA, 16-20 June 2014, AIAA 2014-2753, doi:10.2514/6.2014-2753, 2014.

Grzych, M. L. and Mason, J. G.: Weather conditions associated with jet engine power loss and damage due to ingestion of ice particles: What we've learned through 2009, in: 14th Conference on Aviation, Range, and Aerospace Meteorology, Atlanta, Georgia, USA, 17-21 January 2010, 6.8, 2010.

Heymsfield, A. J.: Ice particle evolution in the anvil of a severe thunderstorm during CCOPE, J. Atmos. Sci., 43, 2463-2478, 1986.
Heymsfield, A. J. and McFarquhar, G. M.: High albedos of cirrus in the tropical Pacific warm pool: microphysical interpretations from CEPEX and from Kwajalein, Marshall islands, J. Atmos. Sci., 53, 2424-2451, 1996.

Heymsfield, A. J. and Palmer, A. G.: Relationships for deriving thunderstorm anvil ice mass for CCOPE storm water-budget estimates, J. Clim. Appl. Meteorol., 25, 691-702, 1986.

Heymsfield, A. J. and Westbrook, C.: Advances in the estimation of ice particle fall speeds using laboratory and field measurements, J. Atmos. Sci., 67, 2469-2482, 2010.

Heymsfield, A. J., Bansemer, A., Field, P. R., Durden, S. L., Stith, J. L., Dye, J. E., Hall, W., and Grainger, C. A.: Observations and parameterizations of particle size distributions in deep tropical cirrus and stratiform precipitating clouds: results from in situ observations in TRMM field campaigns, J. Atmos. Sci., 59, 1-35, 2002.

Heymsfield, A. J., Schmitt, C., and Bansemer, A.: Ice cloud particle size distributions and pressure-dependent terminal velocities from in situ observations at temperatures from $0^{\circ}$ to $-86^{\circ} \mathrm{C}$, J. Atmos. Sci., 70, 4123-4154, doi:10.1175/JAS-D-12-0124.1, 2013.

Houze Jr., R. A.: Mesoscale convective systems, Rev. Geophys., 42, RG4003, doi:10.1029/2004RG000150, 2004.

Jackson, R. C. and McFarquhar, G. M.: An assessment of the impact of antishattering tips and artifact removal techniques on bulk cloud ice microphysical and optical properties measured by the 2D cloud probe, J. Atmos. Ocean. Tech., 30, 2131-2144, doi:10.1175/JTECH-D-14-00018.1, 2014.

Keenan, T.: Hydrometeor classification with a C-band polarimetric radar, Aust. Meteorol. Mag., 52, 23-31, 2003.

Keenan, T., Glasson, K., Cummings, F., Bird, T., Keeler, J., and Lutz, J.: The BMRC/NCAR C-band polarimetric (C-Pol) radar system, J. Atmos. Ocean. Tech., 15, 871-886, 1998.

Kienast-Sjögren, E., Spichtinger, P., and Gierens, K.: Formulation and test of an ice aggregation scheme for two-moment bulk microphysics schemes, Atmos. Chem. Phys., 13, 9021-9037, doi:10.5194/acp-13-9021-2013, 2013.

Knight, C.: The Cooperative-Convective-Precipitation-Experiment (CCOPE), 18 May-7 August 1981, B. Am. Meteorol. Soc., 63, 386-398, 1982.

Korolev, A., Emery, E., and Creelman, K.: Modification and tests of particle probe tips to mitigate effects of ice shattering, J. Atmos. Ocean. Tech., 30, 690-708, doi:10.1175/JTECH-D-12-00142.1, 2013.

Korolev, A., Strapp, J. W., Isaac, G. A., and Emery, E.: Improved airborne hot-wire measurements of ice water content in clouds, J. Atmos. Ocean. Tech., 30, 2121-2131, doi:10.1175/JTECH-D13-00007.1, 2013.

Lawson, R. P., Angus, L. J., and Heymsfield, A. J.: Cloud particle measurements in thunderstorm anvils and possible weather threat to aviation, J. Aircraft, 35, 113-121, 1998.

Lawson, R. P., Jensen, E., Mitchell, D. L., Baker, B., Mo, Q., and Pilson, B.: Microphysical and radiative properties of tropical clouds investigated in TC4 and NAMMA, J. Geophys. Res., 115, D00J08, doi:10.1029/2009JD013017, 2010.

Leroy, D., Fontaine, E., Schwarzenboeck, A., Strapp, J. W., Lilie, L., Delanoë, J., Protat, A., Dezitter, F., and Grandin, A.: HAIC/HIWC field campaign-specific findings on PSD microphysics in high IWC Regions from in situ measurements: Me- 
dian mass diameters, particle size distribution characteristics and ice crystal shapes, Tech. Rep. 2015-01-2087, SAE International, Warrendale, PA, USA, doi:10.4271/2015-01-2087, 2015.

Locatelli, J. D. and Hobbs, P. V.: Fall speeds and masses of solid precipitation particles, J. Geophys. Res., 79, 2185-2197, 1974.

Mapes, B. and Houze Jr., R. A.: An integrated view of the 1987 Australian monsoon and its mesoscale convective systems. I: Horizontal structure, Q. J. Roy. Meteor. Soc., 118, 927-963, 1992.

Mason, J. G. and Grzych, M.: The challenges identifying weather associated with jet engine ice crystal icing, Tech. Rep. 2011-38-0094, SAE International, Warrendale, PA, USA, doi:10.4271/2011-38-0094, 2011.

Mason, J. G., Strapp, J. W., and Chow, P.: The ice particle threat to engines in flight, in: 44th AIAA Aerospace Sciences Meeting, American Institute of Aeronautics and Astronautics (AIAA), 912 January 2006, Reno, Nevada, USA, 2006.

May, P. T. and Keenan, T. D.: Evaluation of microphysical retrievals from polarimetric radar with wind profiler data, J. Appl. Meteorol., 44, 827-838, doi:10.1175/JAM2230.1, 2005.

May, P. T., Mather, J. H., Vaughan, G., Jakob, C., McFarquhar, G. M., Bower, K. N., and Mace, G. G.: The tropical warm pool international cloud experiment, B. Am. Meteorol. Soc., 89, 629646, 2008.

Mazzawy, R. S. and Strapp, J. W.: Appendix D - An interim icing envelope, Tech. Rep. 2007-01-3311, SAE International, Warrendale, PA, USA, doi:10.4271/2007-01-3311, 2007.

McFarquhar, G. M. and Heymsfield, A. J.: Microphysical characteristics of three anvils sampled during the Central Equatorial Pacific Experiment, J. Atmos. Sci., 53, 2401-2423, 1996.

McNaughton, I. I.: The analysis of measurements of free ice and ice/water concentrations in the atmosphere of the equatorial zone, Tech. Rep. MECH. ENG. 283, Farnborough, UK, 1959.

Phillips, V. T. J., Pokrovsky, A., and Khain, A.: The influence of time-dependent melting on the dynamics and precipitation production in maritime and continental storm clouds, J. Atmos. Sci., 64, 338-359, doi:10.1175/JAS3832.1, 2007.

Roques, S.: An airborne icing characterization probe: nephelometer prototype, Smart Mater. Struct., 16, 1784-1788, doi:10.1088/0964-1726/16/5/032, 2007.

Schumacher, C., Houze Jr., R. A., and Kraucunas, I.: The tropical dynamical response to latent heating estimates derived from the TRMM precipitation radar, J. Atmos. Sci., 61, 1341-1358, 2004.

Smith, P.: Equivalent radar reflectivity factors for snow and ice particles, J. Clim. Appl. Meteorol., 23, 1258-1260, 1984.

Steiner, M., Houze Jr., R. A., and Yuter, S. E.: Climatological characterization of three-dimensional storm structure from operational radar and rain gauge data, J. Appl. Meteorol., 34, 19782007, 1995.

Stith, J. L., Haggerty, J. A., Heymsfield, A., and Grainger, C. A.: Microphysical characteristics of tropical updrafts in clean conditions, J. Appl. Meteorol., 43, 779-794, doi:10.1175/2104.1, 2004.

Stith, J. L., Avallone, L. M., Bansemer, A., Basarab, B., Dorsi, S. W., Fuchs, B., Lawson, R. P., Rogers, D. C., Rutledge, S., and Toohey, D. W.: Ice particles in the upper anvil regions of midlatitude continental thunderstorms: the case for frozen-drop aggregates, Atmos. Chem. Phys., 14, 1973-1985, doi:10.5194/acp-141973-2014, 2014.
Strapp, J. W., Chow, P., Maltby, M., Bezer, A. D., Korolev, A., Stromberg, I., and Hallett, J.: Cloud microphysical measurements in thunderstorm outflow regions during Allied/BAE 1997 flight trials, in: 37th AIAA Aerospace Sciences Meeting and Exhibit, American Institute of Aeronautics and Astronautics, Reno, Nevada, USA, 11-14 January 1999, A99-16381, 1999.

Strapp, J. W., Lilie, L. E., Emery, E. E., and Miller, D.: Preliminary comparison of ice water content as measured by hot wire instruments of varying configuration, in: 43rd AIAA Aerospace Sciences Meeting and Exhibit, American Institute of Aeronautics and Astronautics, Reno, Nevada, USA, 10-13 January 2005, AIAA 2005-0860, 2005.

Strapp, J. W., MacLeod, J., and Lilie, L.: Calibration of ice water content in a wind tunnel/engine test cell facility, in: 15th International Conference on Clouds and Precipitation, 7-11 July 2008, Cancun, Mexico, P13.1, 2008.

Toon, O. B., Starr, D. O., Jensen, E. J., Newman, P. A., Platnick, S., Schoeberl, M. R., Wennberg, P. O., Wofsy, S. C., Kurylo, M. J., Maring, H., Jucks, K. W., Craig, M. S., Vasques, M. F., Pfister, L., Rosenlof, K. H., Selkirk, H. B., Colarco, P. R., Kawa, S. R., Mace, G. G., Minnis, P., and Pickering, K. E.: Planning, implementation, and first results of the Tropical Composition, Cloud and Climate Coupling Experiment (TC4), J. Geophys. Res., 115, D00J04, doi:10.1029/2009JD013073, 2010.

Twohy, C. H., Schanot, A. J., and Cooper, W. A.: Measurement of condensed water content in liquid and ice clouds using an airborne counterflow virtual impactor, J. Atmos. Ocean. Tech., 14, 197-202, doi:10.1175/15200426(1997)014<0197:MOCWCI>2.0.CO;2, 1997.

Varble, A., Zipser, E. J., Fridlind, A. M., Zhu, P., Ackerman, A. S., Chaboureau, J.-P., Fan, J., Hill, A., Shipway, B., and Williams, C.: Evaluation of cloud-resolving and limited area model intercomparison simulations using TWP-ICE observations: 2. Precipitation microphysics, J. Geophys. Res., 119, 13-919-13-945, doi:10.1002/2013JD021372, 2015.

Williams, C. R. and Gage, K. S.: Raindrop size distribution variability estimated using ensemble statistics, Ann. Geophys., 27, 555-567, doi:10.5194/angeo-27-555-2009, 2009.

Williams, C. R. and May, P. T.: Uncertainties in profiler and polarimetric DSD estimates and their relation to rainfall uncertainties, J. Atmos. Ocean. Tech., 25, 1881-1887, doi:10.1175/2008JTECHA1038.1, 2008.

Wu, D. L., Austin, R. T., Deng, M., Durden, S. L., Heymsfield, A. J., Jiang, J. H., Lambert, A., Li, J. L., Livesey, N. J., McFarquhar, G. M., Pittman, J. V., Stephens, G. L., Tanelli, S., Vane, D. G., and Waliser, D. E.: Comparisons of global cloud ice from MLS, CloudSat, and correlative data sets, J. Geophys. Res., 114, D00A24, doi:10.1029/2008JD009946, 2009.

Xie, S., Hume, T., Jakob, C., Klein, S. A., Mccoy, R. B., and Zhang, M.: Observed large-scale structures and diabatic heating and drying profiles during TWP-ICE, J. Climate, 23, 57-79, doi:10.1175/2009JCLI3071.1, 2010.

Zeng, X., Tao, W.-K., Powell, S. W., Houze Jr., R. A., Ciesielski, P., Guy, N., Pierce, H., and Matsui, T.: A comparison of the water budgets between clouds from AMMA and TWP-ICE, J. Atmos. Sci., 70, 487-503, doi:10.1175/JAS-D-12-050.1, 2013. 